\title{
INFLUÊNCIA DO FOTOPERÍODO E RADIAÇÃO GAMA NA ETOLOGIA DA OVIPOSIÇÃO DE Ceratitis sapitata (WIEDEMANN, 1824) (DIPTERA-TEPHRITIDAE)
}

VALDEMAR LUIZ TORNISIELO

Orientador: Prof. Dr. FREDERICO MAXIMILIANO WIENDL

Dissertação apresentada à Escola Superior de Agricultura "Luiz de Queiroz", da Universidade de São Paulo, para obtenção do título de Mestre em Ciências Biológicas. Área de Concentração: Entomologia.

PIRACICABA

Estado de São Paulo - Brasil

Dezembro - 1985 
.ii.

A meus pais e irmãos

$$
\text { OFERECO }
$$

\section{À Jūlia \\ Raymond}

Alex

Daniel

Bruno,

DEDICO 


\section{AGRADEC IMENTOS}

- A minha querida esposa Júlia, pelo incentivo e compreensão.

- Ao Prof. Dr. Frederico M. Wiendl, pelo apoio e orientação.

- Ao Centro de Energia Nuclear na Agricultura pelas facilidades concedidas.

- Ao Conselho Nacional de Desenvolvimento Cientifico e Tecnológico (CNPq) pela Bolsa concedida.

- Ao Departamento de Entomologia da ESALQ, pelos conhecimentos transmitidos.

- Ao Dr. Júlio M. M. Walder, pelas críticas e sugestões .

- À Sra. Diva Athié pela versão do Resumo para o inglês.

- À SONAR - Serviços de Datilografia S/C Ltda. pelos serviços de datilografia e impressão e ao Sr. Antonio Alfredo Lacerda pelos desenhos.

- Ao pessoal da Seção de Ecologia, Gilberto, Edson, Rosângela e Odair pelos auxílios prestados durante a realização desta pesquisa. 
.iv.

- Ao Sr. Rubens Ignes Alioni pelo incentivo e amizade.

- Aos colegas da Seção de Entomologia, pela amizade e espirito de colaboração.

- Para não errar por omissão, agradeço a todos que, embora não citados, participaram direta ou indireta mente na realização deste trabalho. 


\section{INDICE}

pāgina

RESUMO vi

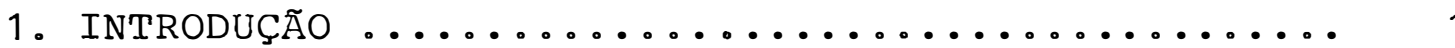

2. REVISÃO DE LITERATURA .......................... 4

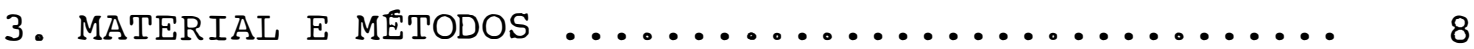

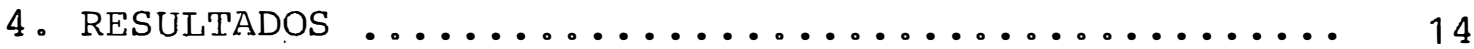

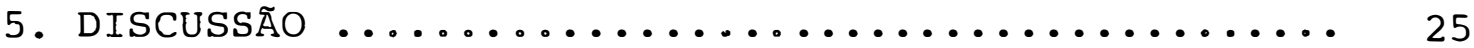

5.1. Etapa 1 - Insetos não irradiados ......... 25

5.2. Etapa 2 - Insetos irradiados com 10 Gy ..... 34

6. CONCLUSÕES ........................... 43

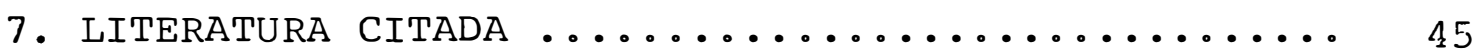


.vi.

\author{
INFLUENCIA DO FOTOPERIODO E RADIAÇÃO GAMA \\ NA ETOLOGIA DA OVIPOSIÇÃO DE Ceratitis capitata \\ (Wiedemann, 1824) (DIPTERA - TEPHRITIDAE)
}

\author{
Autor: VALDEMAR LUIZ TORNISIELO \\ Orientador: FREDERICO MAXIMILIANO WIENDL
}

\title{
RESUMO
}

A influência do fotoperiodo na etologia da oviposição da mosca do Mediterrāneo, C. capitata (Wied., 1824 ) (Dip. Tephritidae) foi estudada em condições de labora tório, na Seção de Entomologia do Centro de Energia Nuclear na Agricultura (CENA/USP), Piracicaba, SP, Brasil. Os insetos adultos foram submetidos aos seguintes fotoperíodos: 12: $12 ; 6: 18 ; 18: 6 ; 24: 0$ e $0: 24$ (1uz-escuro), alternando-se a se quência de luz-escuro, conforme cada uma das dez gerações es tudadas, com o objetivo de verificar o efeito do fotoperíodo e das radiações gama do cobalto 60 , no comportamento de oviposição da mosca-do-Mediterrâneo. Observou-se uma estreita dependência da luz para a oviposição desse inseto, notando-se que durante os períodos escuros, esporadicamente, ocor-

reu postura e que o maior número de ovos foram postos entre 3 e 4 horas após o início do periodo luminoso. A radiação 
vii.

gama a que foram submetidos os insetos influi negativamente na oviposição, reduzindo o número de ovos. Não se observou, entretanto, neste experimento, influência da radiação sobre a etologia de oviposição da mosca-do-Mediterrâneo. 
INFLUENCE OF PHOTOPERIOD AND GAMA RADIATION ON THE ETHOLOGY OF Ceratitis capitata

(Wied enann, 1824) (DIPTERA-TEPHRITIDAE) OVIPOSITION

Author: VALDEMAR LUIZ TORNISIELO

Adviser: FREDERICO MAXIMILIANO WIENDL

\section{SURMARY}

The influence of the photoperiod in the ethology on C. capitata (Wied., 1824) (Dip. Tephritidae) oviposition was studied under laboratory conditions, at the Entomology Section of 'Centro de Energia Nuclear na Agricultura", University of São Paulo (CENA/USP), Piracicaba, SP, Brazil. Adult insects were submitted to the following photoperiods: 12:12, 6:18, 18:6, 24:0 and 0:24 (light-dark), on an alternate light-dark sequence, in accordance with the ten generations studied. The effect of photoperiod and 60Cobalt gamma radiation on the behaviour of the Medfly oviposition was also investigated. A close dependence of oviposition on light was noted, and that during dark periods egging occurred very sporadically. It was also noted that a larger number of eggs were laid between 3-4 hours after the beginning of the light period. Gamma radiation had a 
. ix. negative influence on the oviposition, reducing the number of eggs, however, no influence of gamma radiation on the ethology of the Medfly oviposition was noted. 


\section{INTTRODUCÁAO}

A cultura de citros no Brasil se reveste da maior importância, com regiões destacadas nos Estados de são Paulo, Minas Gerais e Rio de Janeiro.

A produção brasileira se destina tanto ao mer cado interno, das frutas "in natura", como industrializadas em forma de suco concentrado, em grande parte exportado.

A citricultura no Brasil é uma das principais atividades agrícolas, tanto pela extensão da área cultivada, como pela produção. Sua importância tem aumentado nos últimos anos, principalmente após as geadas de $83 / 84$ nos EUA, que afetaram drasticamente a produção, permitindo ao Brasil exportar frutos frescos e suco concentrado em maior quantidade, atingindo em 1983, US\$ 624 milhões (PROGNOSTICO IEA, 1984)。 
Dentre os problemas da citricultura, pode-se citar o ataque dos insetos, como um dos principais. E dentre estas pragas, destaca-se a ação das moscas das frutas, cuja espécie mais prejudicial, Ceratitis capitata (Wied, 1824), foi introduzida no início deste século, quando foi constatada pela primeira vez em 1901 (MARICONI e IBA, 1955). Segundo estes autores, esta praga tem como hospedeiros alter nativos, pêssego, goiaba, pera, ameixa, manga, café, além de frutos silvestres que funcionam como hospedeiros da população "estoque", na épocia da entre-safra. A referida espécie adaptou-se muito bem às nossas condições verificando-se no campo várias gerações durante o ano.

Os prejuízos são ocasionados pelas larvas da mosca, que destroem a polpa, permitindo a instalação de podridões ocasionadas por fungos e bactérias. Mesmo as raras posturas que não dão eclosão a larvas, ou aquelas cujas larvas morrem, causam prejuízos pelo aparecimento de manchas es curas na casca, depreciando e dificultando a comercialização dos frutos (MARICONI e IBA, 1955).

$\mathrm{Na}$ tentativa de resolver este problema, os agricultores têm utilizado em larga escala agrotóxicos, que permitem controlar a praga, mas ao mesmo tempo provocam efei tos indesejáveis, inerentes a este tipo de controle, como a presença de residuos tanto nos frutos consumidos "in natura", como nos sucos concentrados. Levam também ao extermínio de 
insetos úteis, intoxicações nos operadores, além da contaminagão ambiental. Aliado a isto, ainda temos o custo destes produtos, que diminui a rentabilidade desta cultura.

$$
\text { Por estes motivos, têm-se estudado meios que }
$$
possibilitem a redução de perdas e a melhoria da qualidade dos frutos, com reduções de custos e danos ao ambiente, evitando-se ainda riscos de intoxicação.

O propósito do presente trabalho é de fornecer subsidios para uma série de métodos de contrôle de c. ca pitata, assim como possibilitar uma maior eficiência destes. Nas condições ecológicas de nosso país há necessidade de um estudo mais detalhado e, a fim de se aplicar ou estudar a viabilidade da Técnica do Inseto Estéril e mesmo outros méto dos de contrôle, se fazem necessários estudos básicos. Um destes exemplos é o estudo da influência do fotoperiodo na oviposição da mosca-do-Mediterrâneo, visando determinar a in fluência na postura da espécie e uma possivel alteração deste comportamento, após irradiação com raios gama. Partindo ainda do pressuposto ser a oviposição uma das característi cas mais facilmente afetadas por fatôres ambientais e fisiológicos, o presente trabalho objetiva mostrar se ocorrem alterações nos hábitos normais dos insetos, após a sua irradiação. 
.4 .

\section{REVISÃO DE LITERATURA}

o estudo da influência do fotoperíodo em inse tos teve início com o trabalho feito por MARCOVITCH (1924), com o afideo Dysaphis plantaginea. O autor relata a influên cia do fotoperíodo como estímulo ao aparecimento de formas a ladas.

GREENFIELD e KARANDINOS (1976) estudaram O

ritmo diārio de oviposição em Synanthedon pictipes utilizando fotoperiodo constante de 16 L:8E e termoperiodos variáveis. Verificaram que o nümero de ovos postos variou quanti tativamente com o termoperiodo.

Pesquisadores como HSIAO (1978), BENSCHOTER

(1970), verificaram a atividade circadiana em várias espécies de Heliothis. Outros como PITTENDRIGH e MINIS (1972) verificaram a influência do período de luz sobre a longevidâ de de Drosophila sp. 
HAVERTY e WARE (1970) verificaram a interdependência do fotoperíodo e da taxa de radiação " $\mathrm{x}$ " sobre Pec tinophora gossypiela.

PARRA et alii (1983) em estudo feito com Diatraea saccharalis verificaram que lagartas submetidas a foto fase de 24 horas, deram origem a pupas mais leves e maior percentagem de adultos deformados, verificando ainda que a fase larval é a mais sensivel às mudanças do fotoperiodo.

FERREIRA e PARRA (1985) verificaram que o desenvolvimento de Mocis latipes é influenciada pelo fotoperío do. Tanto as lagartas como as pupas tiveram um menor periodo larval e pupal quando submetidas a 14 horas de luz por dia. Observaram ser a fase larval menos sensivel que a pupal. Em completa escuridão, o período é sensivelmente mais longo.

CONSTANTINOU (1984) estudou a influência do fotoperiodo de 12 horas de luz em Triatoma phyllosoma, T. infestans e panstrongylus megistus e constatou que a oviposi ção inicia e tem o seu pico de número de ovos logo após o início da fase escura. Verificou ainda que mesmo em escotofase de 24 horas os insetos mantém o rítmo circadiano.

ALLEMAND e DAVID (1984) trabalharam com duas linhagens naturais de Drosophila melanogaster, sendo uma linhagem tropical Africana e outra Européia. Constataram para 
cada linhagem um rítmo circadiano de ovipósição próprio.

ALLEMAND et alii (1984) apresentaram uma análise genética do ritmo circadiano de oviposição, constatando que mesmo após 100 gerações, as drosófilas apresentavam o rítmo circadiano da linhagem original. Estudaram ainda a substituição cromossômica entre as linhagens e verificaram uma hereditariedade poligenética do ritmo circadiano.

zOTOV (1983) trabalhando com Coccinella septempunctata, verificou que estes coleópteros eram inativos durante a fase escura e que o início do fotoperíodo foi esti mulante para as atividades circadianas; verificou ainda que as temperaturas do amanhecer e entardecer influem nas atividades dos insetos, mas não interferem nos rítmos circadianos.

$$
\text { LAUDEHO et alii (1978) em trabalho realizado }
$$

com Dacus oleae, utilizando azeitonas do campo infestadas por esta mosca, verificaram que o início do amanhecer, estimula a saída das larvas no estágio de pré-pupa dos frutos. o pico de saída das larvas se dá ao redor das 10 horas da manhã, caindo progressivamente até o anoitecer. No período no turno não foram verificadas saídas das larvas dos frutos.

CAUSSE (1974) estudou a atividade circadiana de larvas de último instar de Ceratitis capitata, no estágio 
.7 .

de pré-pupa. Com fotoperíodo de 12:12 LE, O autor verificou que o pico de saída das larvas para pupação se deu no início do periodo de luz. O rítmo circadiano permaneceu constante quando as larvas foram mantidas em período de escuro ou luz constante. 
.8.

\section{MATERIAL E M.MÉTODOS}

Este trabalho teve seu desenvolvimento na seção de Entomologia do Centro de Energia Nuclear na Agricultụ ra, CENA-USP, Piracicaba, SP 。

Os insetos utilizados foram provenientes da criação massal da Seção de Entomologia do CENA, mantida em temperatura ambiente, entre 24 e $28^{\circ} \mathrm{C}, \quad \mathrm{com}$ fotofase constante de 14 horas.

Os adultos da criação massal foram mantidos em gaiolas de oviposição, possuindo duas faces laterais em tecido tipo "voil", e que foram iluminadas com lâmpadas fluo rescentes GE 20 W F20 LD, sendo ligadas às 6:00 horas da manhã por meio de um "Timer".

Os ovos foram recolhidos através de uma calha em PVC, mantida com água,abaixo das gaiolas. Os ovos assim 
coletados eram colocados em funil de Buchner de vidro sinterizado, com água e fluxo de ar ascendente, até à eclosão das larvas. Em seguida as larvas eram colocadas em caixas plásticas com dieta artificial e mantidas até o último instar, quando as caixas eram abertas, e as larvas saiam voluntariamente para sua transformação em pupas.

$$
\text { Utilizaram-se aproximadamente } 8.500 \text { insetos }
$$

com idade até 12 horas após a emergência. Para cada fase do experimento, os insetos eram postos em uma gaiola especial de oviposição, medindo 30 × 40 x $50 \mathrm{~cm}$, com uma faixa vertical útil de postura de $2 \mathrm{~cm}$ de largura, feita em tecido tipo "voil" (Figura 1). O restante da superficie da gaiola ficou coberta com tecido negro, obrigando os insetos a fazerem pos tura somente na faixa iluminada através de uma lâmpada fluorescente, já descrita anteriormente e disposta paralelamente a $30 \mathrm{~cm}$ da faixa de postura.

Esta gaiola foi mantida em uma câmara climatị zada, marca CONVIRON com temperatura de $25 \pm 2{ }^{\circ} \mathrm{C}$ e umidade relativa de $80 \pm 5 \%$, sendo estes parâmetóros registrados em grāficos do contrôle da câmara.

Os insetos foram mantidos, desde a emergência até o início da postura, em fotoperiodo totalmente irregular, procurando-se evitar com isto o condicionamento dos insetos para um determinado fotoperíodo. Os adultos foram alimentados desde a emergência, com proteína hidrolizada "Vegamine 


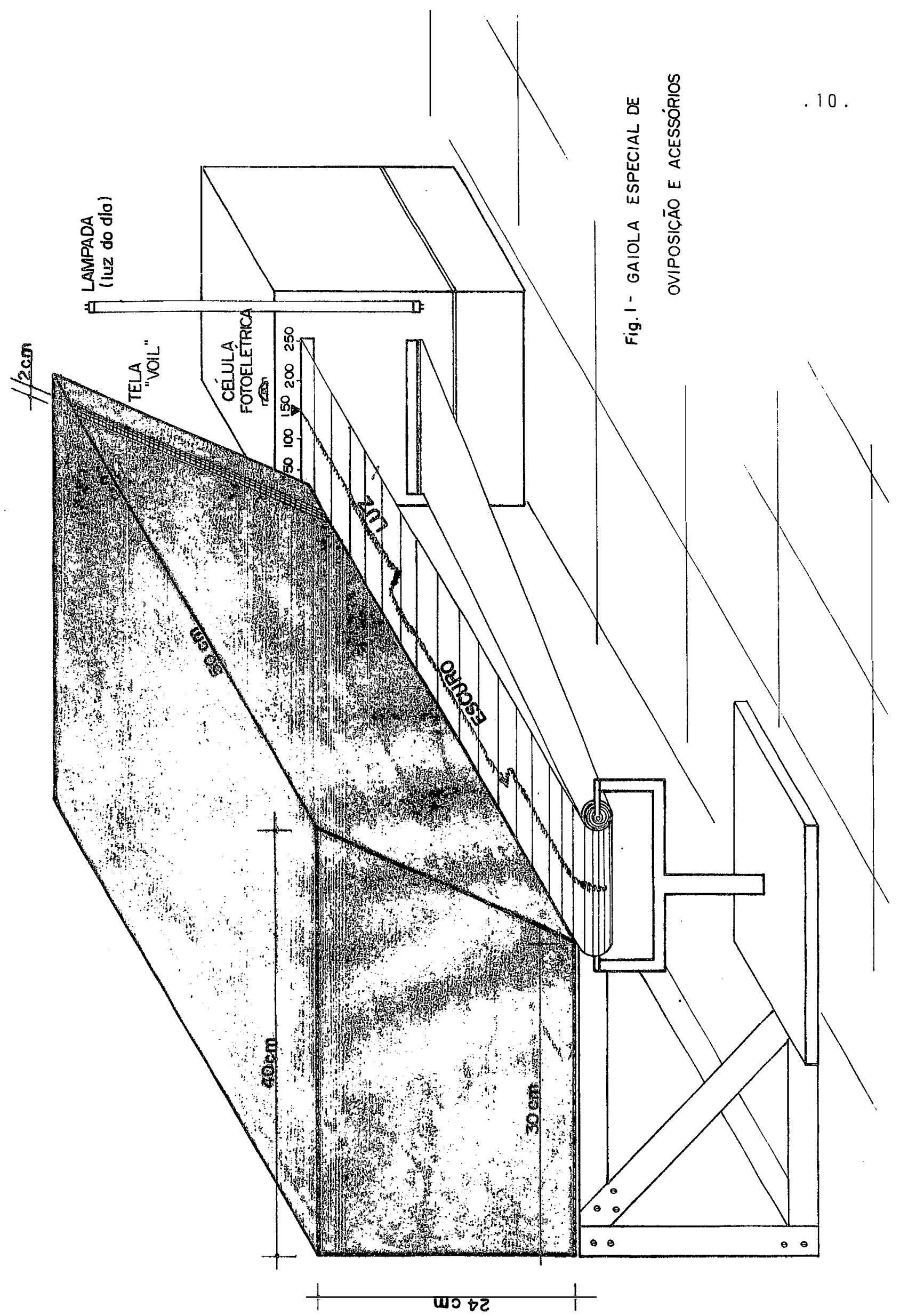


003" e açúcar em forma de pasta, sendo fornecida água destilada através de algodão umidecido.

Após o início da postura os fotoperiodos iniciavam as 6 horas, simulando aproximadamente o mesmo horário do amanhecer do dia, que é em torno das 5:10 às 6:50 h duran te o ano (ENGLERT, 1974)。

A postura foi coletada sobre uma esteira de papel, com movimento contínuo de $2 \mathrm{~cm}$ por hora, durante todo o experimento. Fez-se a contagem do número de ovos para cada hora do dia.

O período de "Luz-Escuro", foi registrado sobre o paṕel de coleta dos ovos através de um registrador mecânico adaptado com célula fotoelétrica, que funcionou, assim como o sistema de movimento do papel coletor de ovos, 1 i gado a baterias, evitando-se assim, erros na contagem dos ovos por falta de energia elétrica (Figura 1).

o experimento foi montado de maneira a permitir, uma sequência de fotoperíodos. Cada fase iniciou com fotoperíodo diferente e em forma de rodízio (Tabela 1), procurando-se minimizar os efeitos de "choque" pela mudança brusca de fotoperíodo, já que em cada fase, os insetos foram expostos a diferentes sequências de fotoperiodos. Cada foto período teve a duração de 4 dias consecutivos, portanto, cada fase do trabalho correspondeu a 20 dias de oviposição. Nas fases 
.12 .

TABEIA 1. Fotoperiodos e sua sequência, a que foram submetidos os adultos de $C$. capitata, após o início da postura, durante cada uma das fases do trabalho.

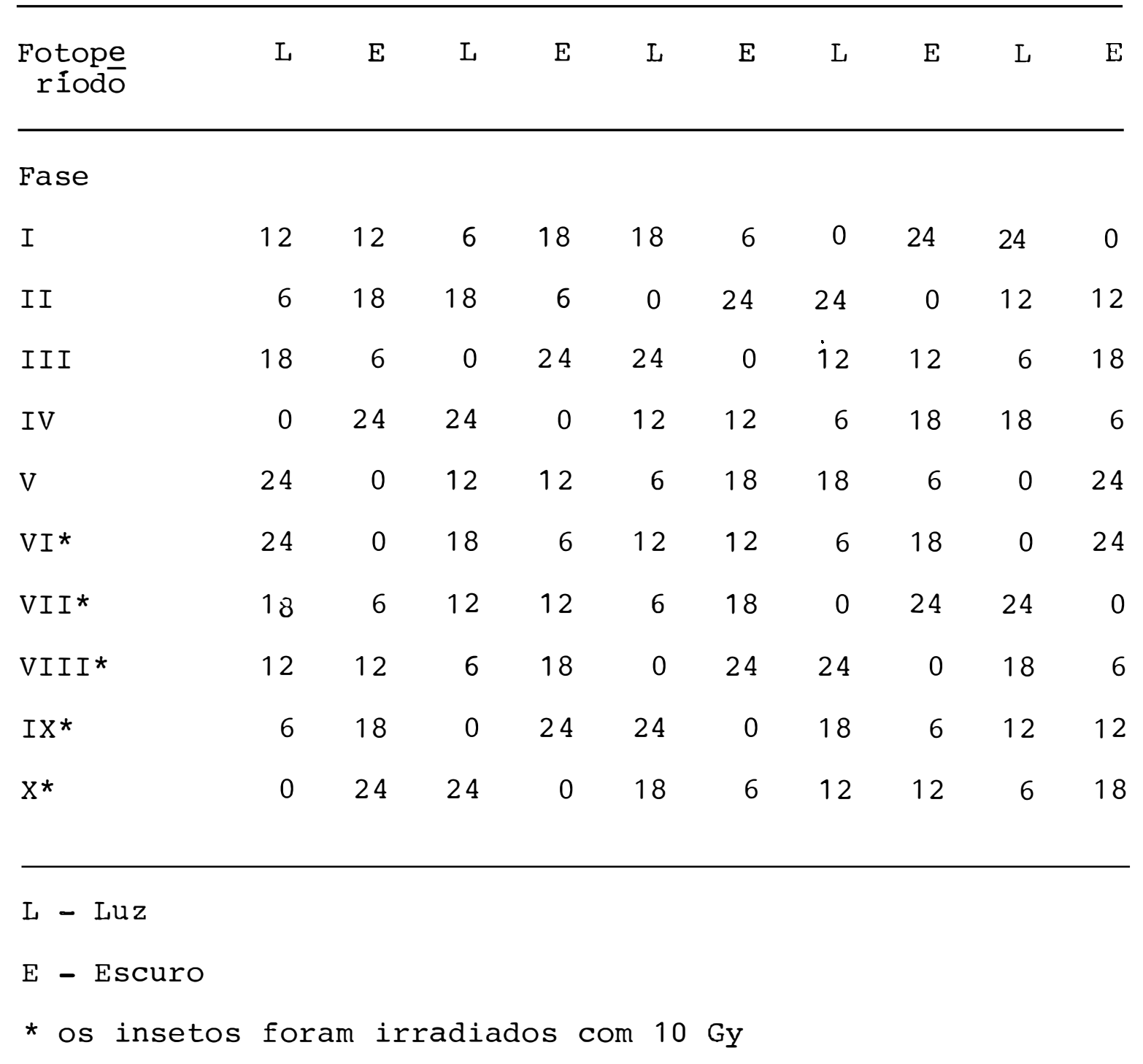


de I a V, os insetos utilizados foram normais.

Nas fases de VI a X foram irradiados com radiações gama no 6! dia da fase pupal com uma dose de 10 Gy à taxa de 3,4 kGy/h, pretendendo-se com isto, verificar uma possivel influência das radiações ionizantes no comportamento de postura.

Para irradiação das pupas, utilizou-se um irradiador de ${ }^{60}$ Co tipo. Gammabeam - 650 da "Atomic Energy of Canada", Otawa, com atividade de $17.743 \mathrm{Ci}$ no início dos experimentos. As pupas foram acondicionadas em um frasco de vidro redondo, medindo $10 \mathrm{~cm}$ de altura por $8 \mathrm{~cm}$ de diâmetro, colocado no centro do irradiador. Para cada fase do experimento, calcularam-se os tempos de exposição no irradiador, de maneira a evitar diferenças nas taxas de dose e erros de dosagem, devidos ao decaimento radioativo do ${ }^{60} \mathrm{Co}$. 


\section{Resertadios}

Os dados obtidos na 1 a etapa do trabalho, onde insetos não irradiados foram utilizados, são apresentados nas Tabelas numeradas de 2 a 6 , fases I a V respectivamente. Nelas aparecem os valores numéricos dos ovos obtidos nos intervalos de uma hora e sua correspondência com a hora do dia. Aparecem também os respectivos fotoperíodos, a que foram sub metidos os adultos de Ceratitis capitata (Wied., 1824), após o início da postura.

Os dados obtidos na 2 a etapa do trabalho, cujos insetos foram irradiados no 69 dia da fase pupal, com uma dose de 10 Gy de raios gama, são apresentados nas Tabelas numeradas de 7 a 11 , fases VI a X respectivamente. Nelas aparecem os valores numéricos dos ovos obtidos nos inter valos de uma hora, e sua correspondência com a hora do dia. Aparecem também os respectivos fotoperíodos, a que foram sub metidos os adultos de C. capitata, após o início da postura. 


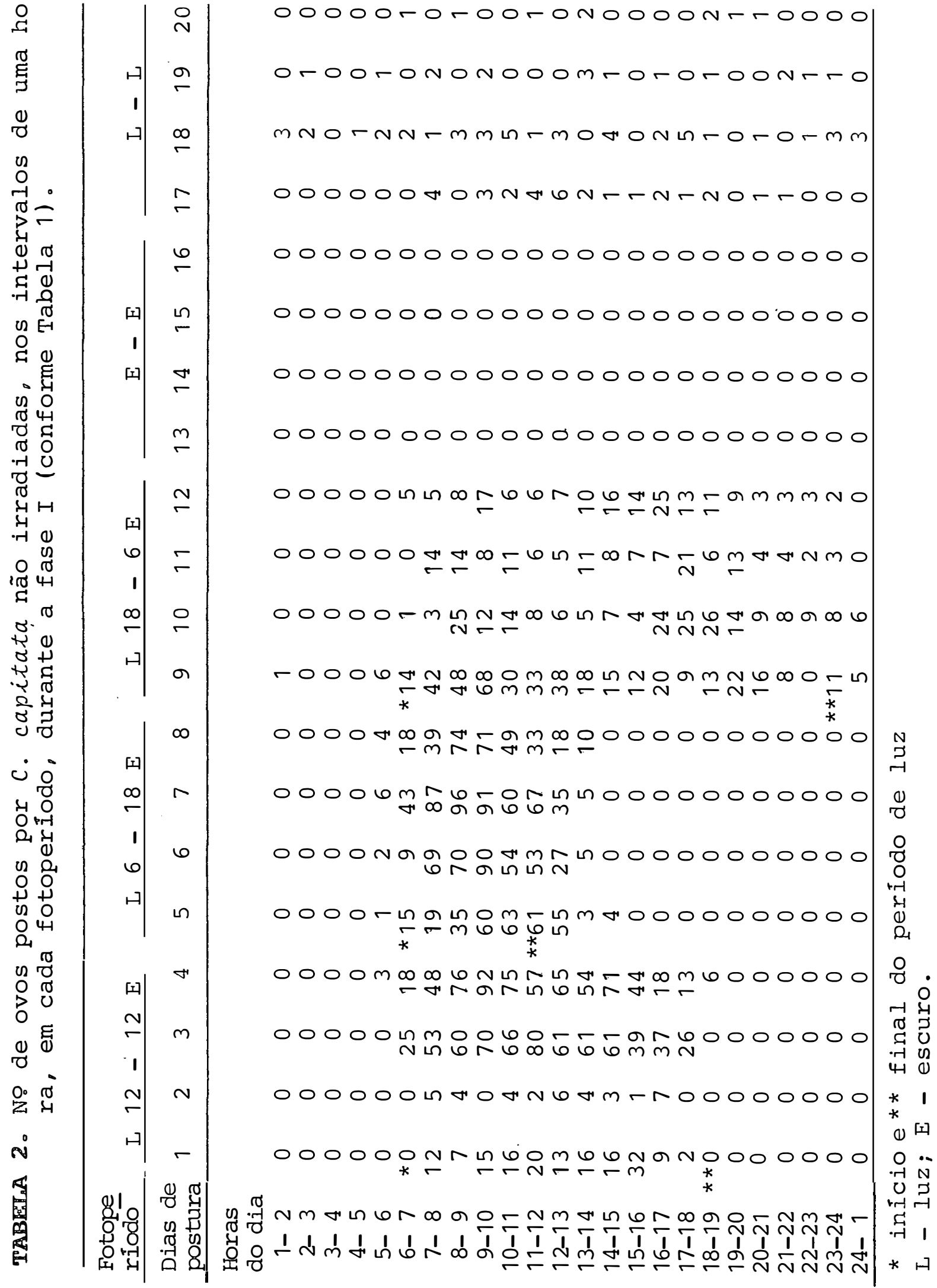


.16.

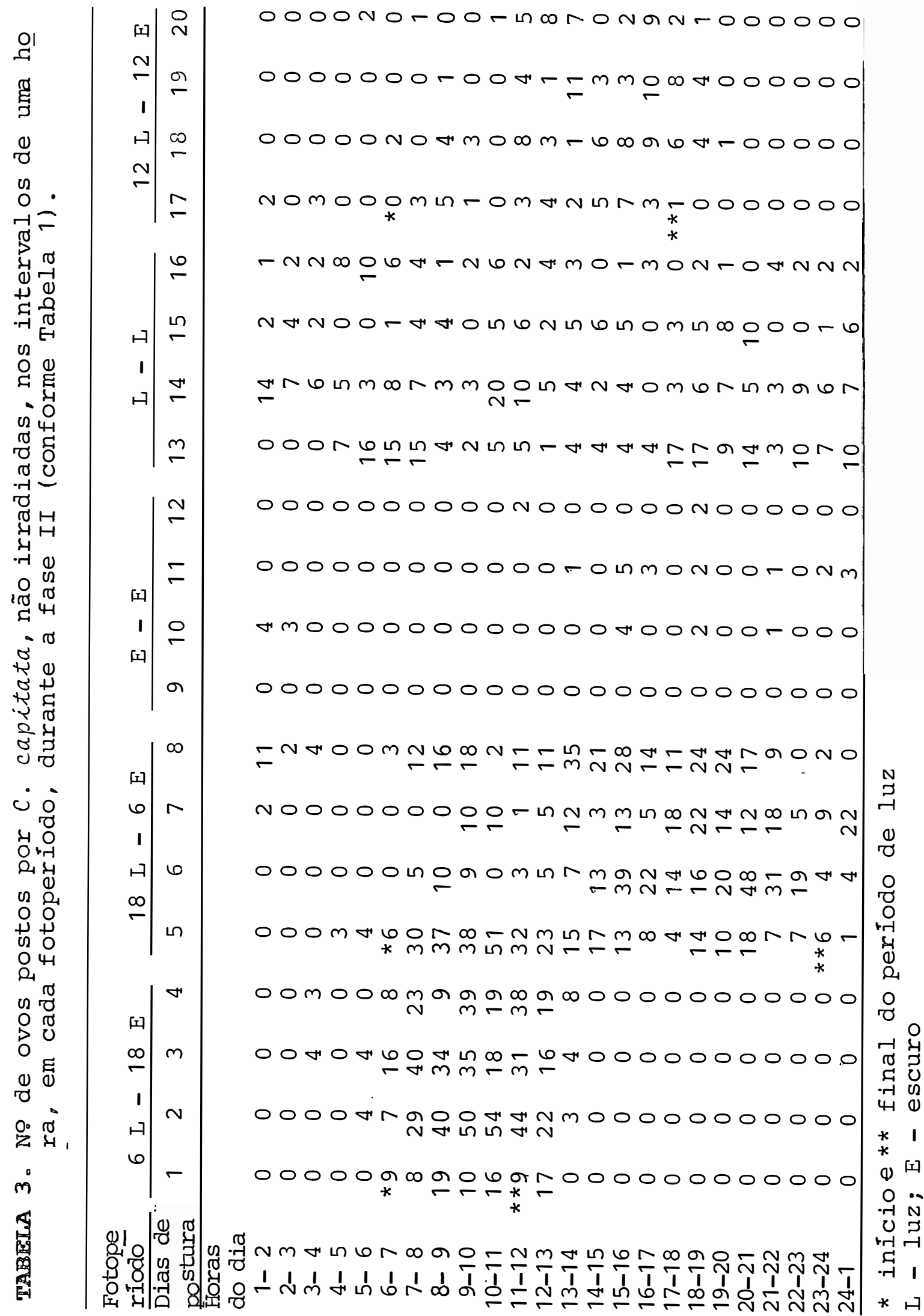




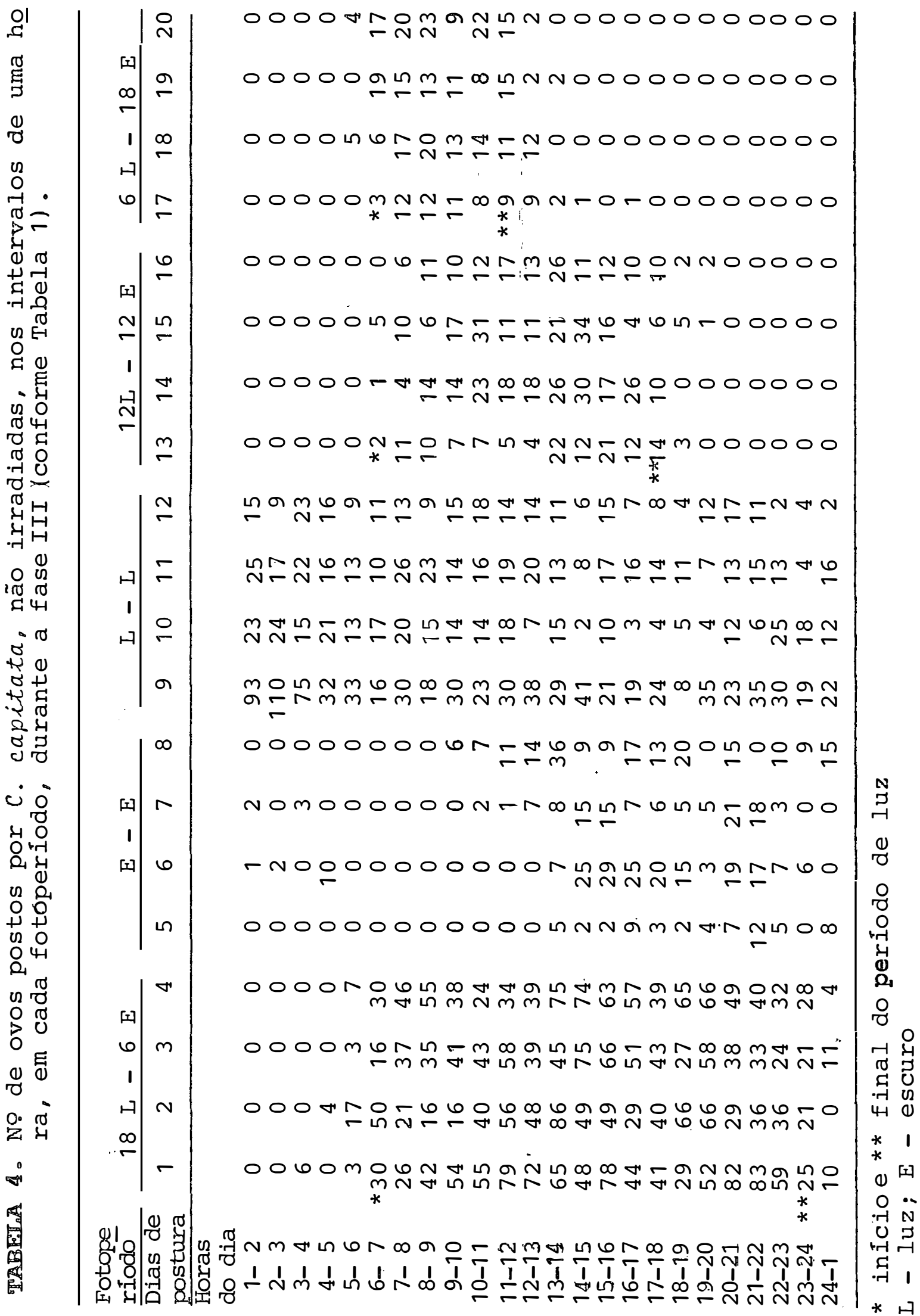




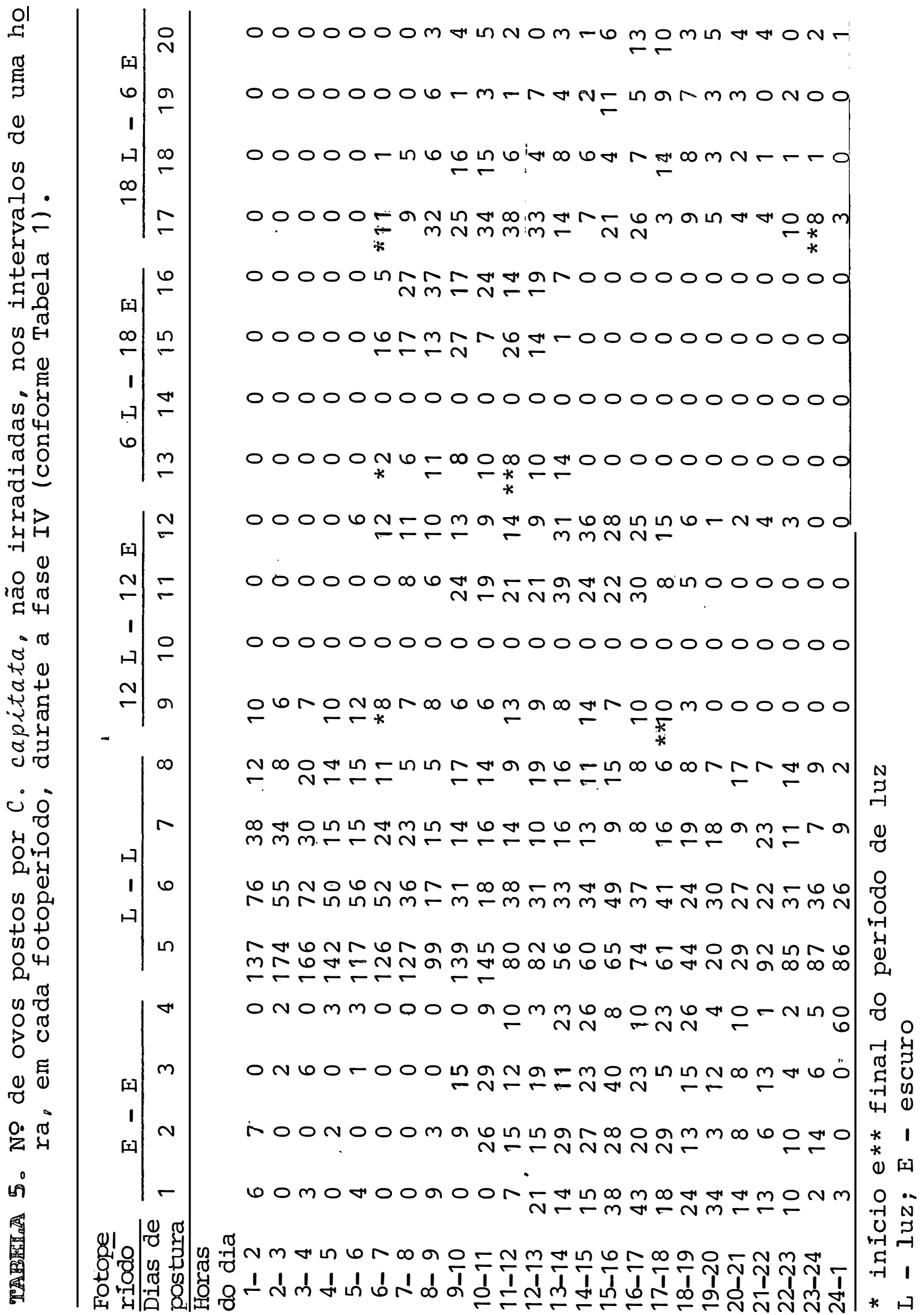




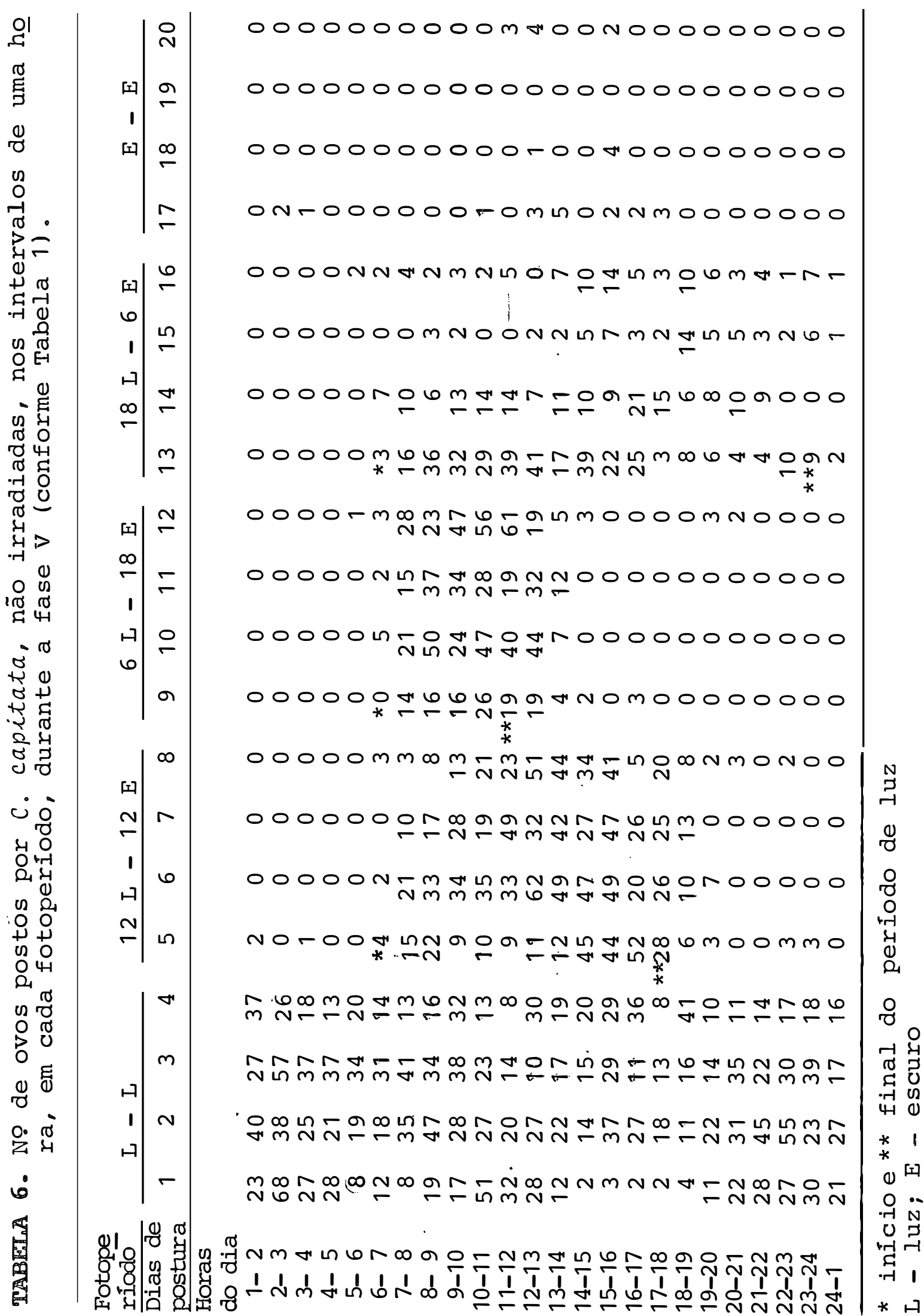




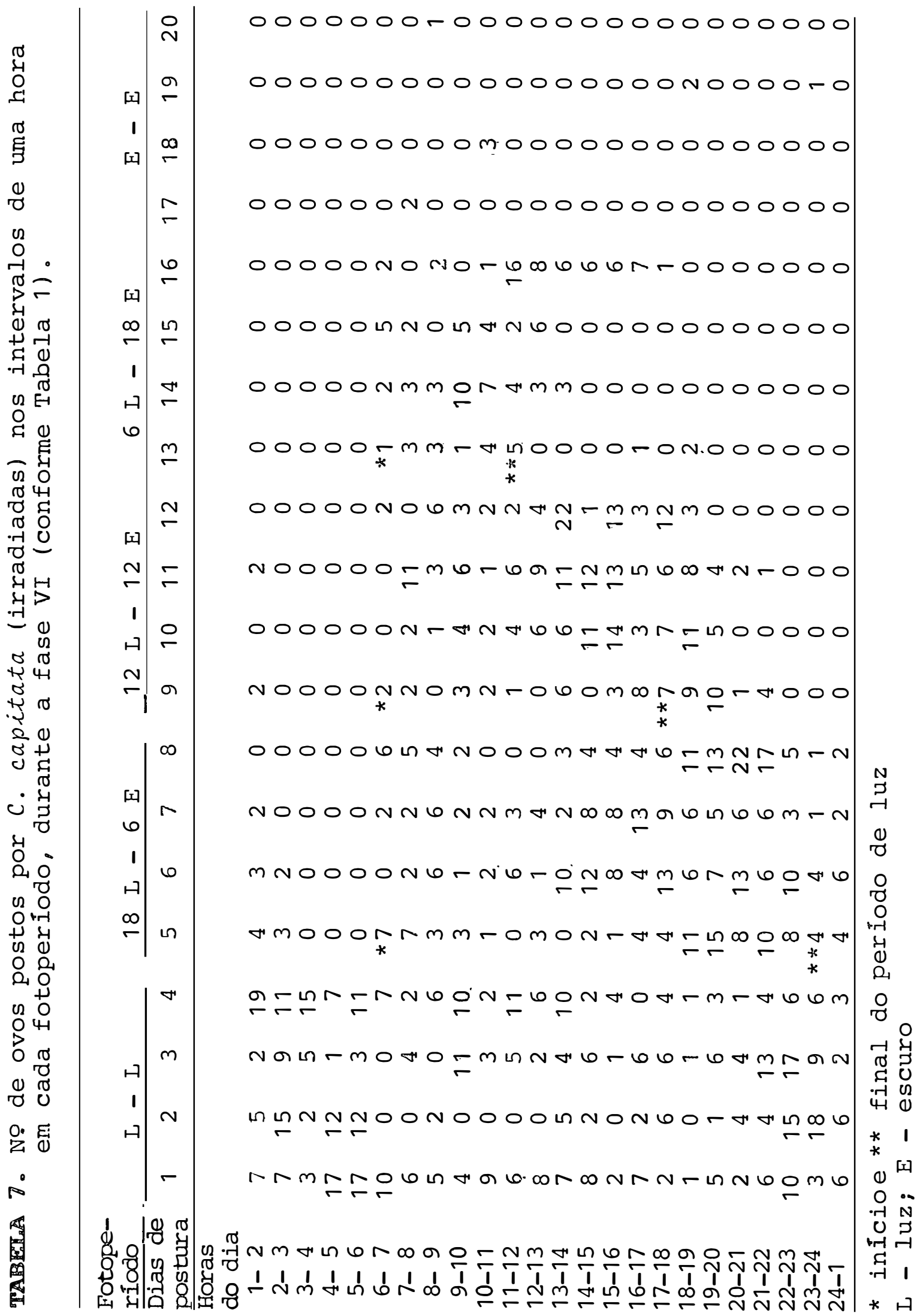




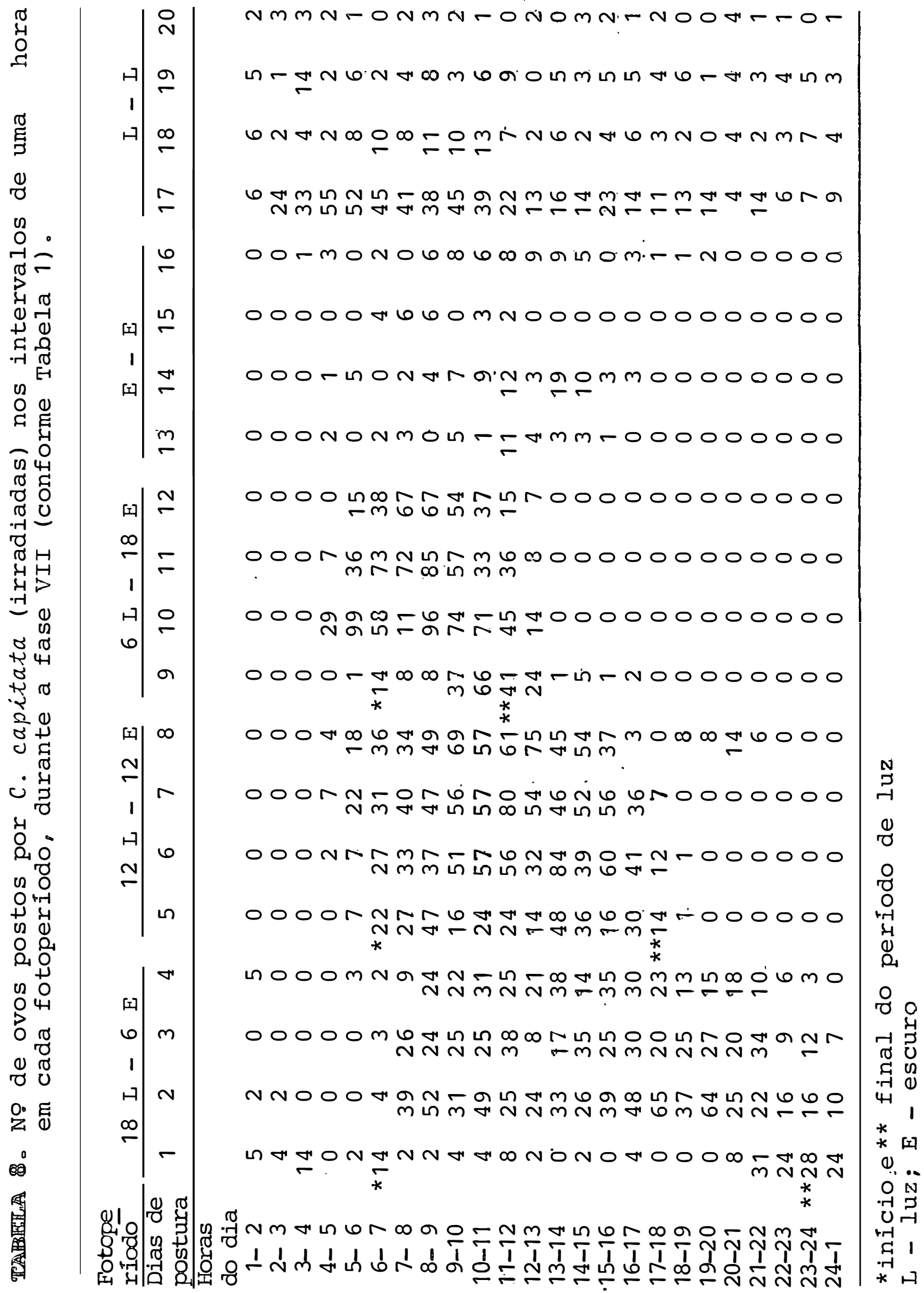




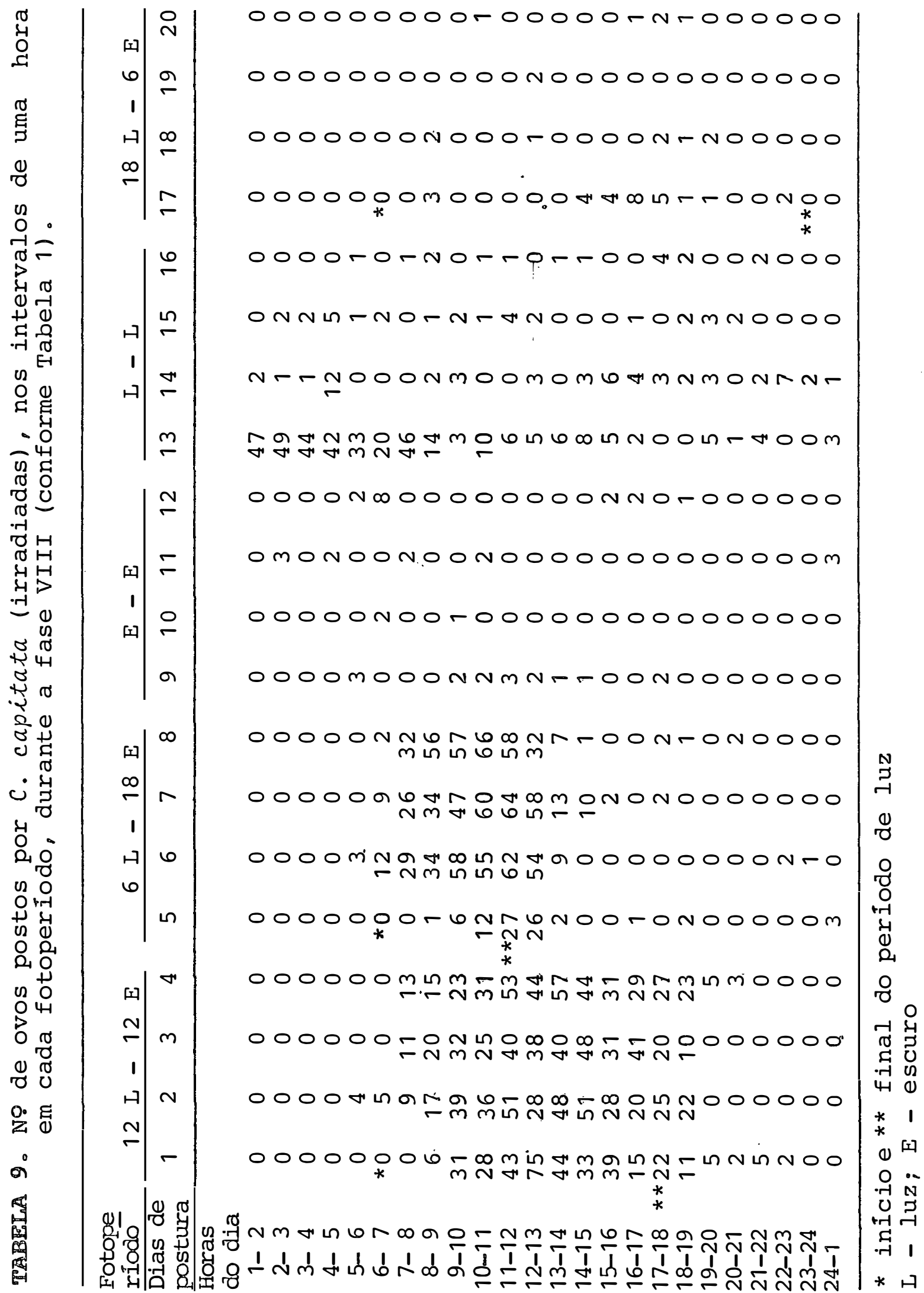




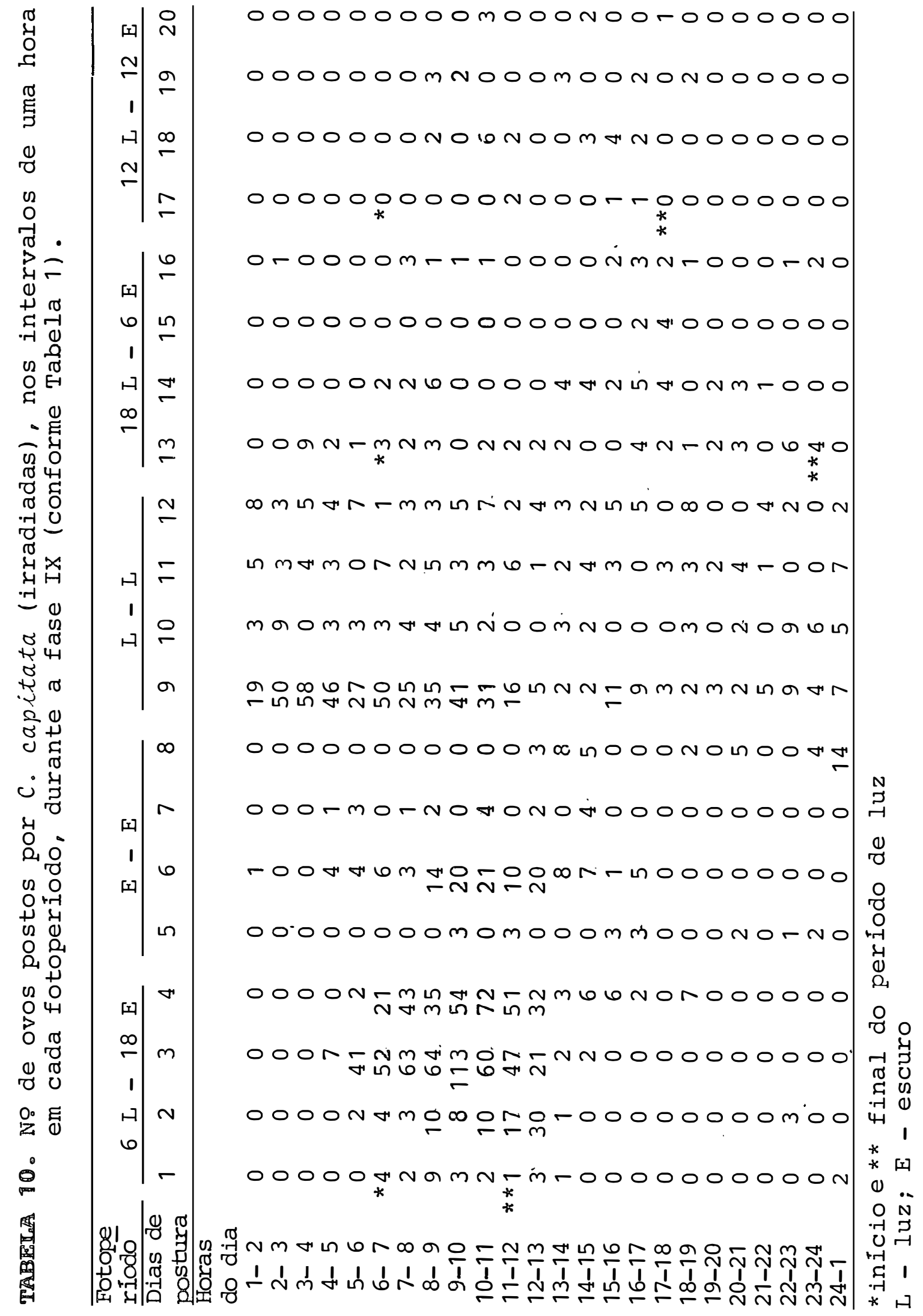




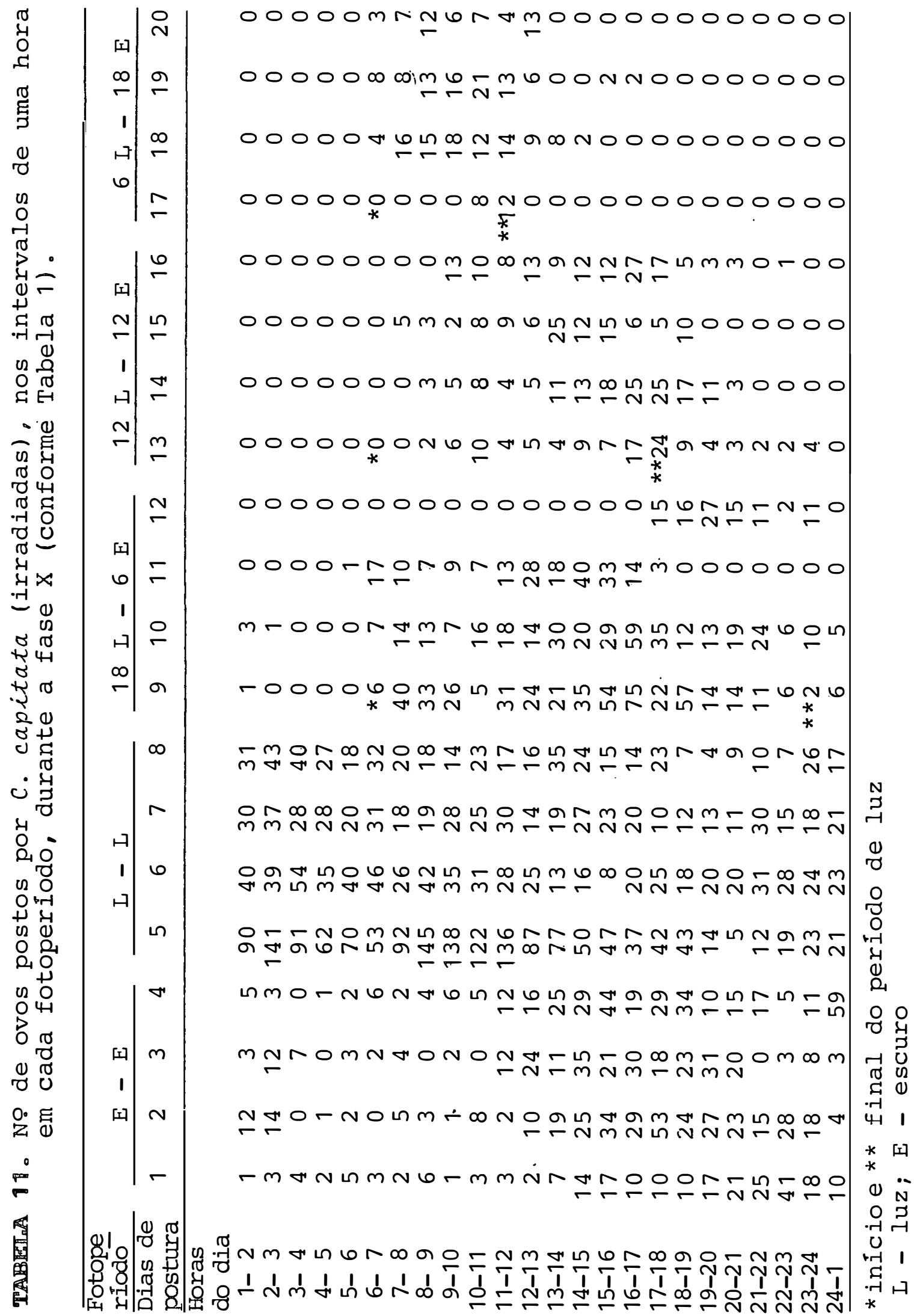




\section{DISCUSSÃO}

5.1. Etapa 1 - Insetos não irradiados

A partir dos dados da Tabela 2, construiu-se o gráfico da Figura 2 e a Tabela 12. Através destes, pode-se observar a dependência do período de luz para que ocorresse oviposição, notando-se nitidamente uma distribuição da postura durante o período luminoso. Observa-se ainda que nesta fase, nos quatro dias sem luz, não houve postura.

Com os dados obtidos na fase II, Tabela 3, elaboraram-se as médias dos 4 dias de postura de cada fotoperío do (Tabela 13) e construiu-se o gráfico da Figura 3, onde se observa estreita dependência entre o período de luz e a oviposição, semelhante à fase I. Observando-se melhor o gráfico da Figura 3, no 58 dia de postura, verifica-se acomodação de C. capitata ao fotoperiodo anterior. Nota-se ainda neste gráfico, posturas realizadas durante $\circ$ fotoperiodo 
.26 .

$\mathbb{T} \mathbb{A} B \mathbb{R}^{\mathrm{A}} \mathbb{\mathbb { A }}$ 12. Média do no de ovos postos por C.. capitata, não irradiadas, nos intervalos de uma hora, em cada fotoperíodo, durante a fase I (conforme Tabela 1).

\begin{tabular}{|c|c|c|c|c|c|c|}
\hline \multirow{2}{*}{\multicolumn{2}{|c|}{$\begin{array}{l}\text { Hora do } \\
\text { dia }\end{array}$}} & \multicolumn{5}{|c|}{ Fotoperiodo } \\
\hline & & $12 L-12 E$ & $6 L-1.8 E$ & $18 L-6 E$ & $E-E$ & $L-L$ \\
\hline 1 & - & 0 & 0 & 0,25 & 0 & 0,75 \\
\hline 2 & -3 & 0 & 0 & 0 & 0 & 0,75 \\
\hline 3 & -4 & 0 & 0 & 0 & 0 & - \\
\hline 4 & -5 & 0 & 0 & 0 & 0 & 0,25 \\
\hline 5 & -6 & 0,75 & 3,25 & 1,50 & 0 & 0,75 \\
\hline 6 & -7 & $10,75 *$ & $21,25 *$ & $5,00 *$ & 0 & 0,75 \\
\hline 7 & -8 & 29,50 & 53,50 & 16,00 & 0 & 1,75 \\
\hline 8 & -9 & 36,75 & 68,75 & 23,75 & 0 & 1,00 \\
\hline & -10 & 44,25 & 78,00 & 26,25 & 0 & 2,00 \\
\hline 10. & -11 & 40,25 & 56,50 & 15,25 & 0 & 1,75 \\
\hline 11 & -12 & 39,75 & $53,50 * *$ & 13,25 & 0 & 1,50 \\
\hline & -13 & 36,25 & 33,75 & 14,00 & 0 & 2,25 \\
\hline 13 & -14 & 33,75 & 5,75 & 11,00 & 0 & 1,75 \\
\hline 14 & -15 & 37,75 & 1,00 & 11,50 & 0 & 1,50 \\
\hline 15 & -16 & 29,00 & 0 & 9,25 & 0 & 0,25 \\
\hline 16 & -17 & 17,75 & 0 & 19,00 & 0 & 1,25 \\
\hline 17 & -18 & $10,25 * *$ & 0 & 17,00 & 0 & 1,50 \\
\hline 18 & -19 & 1,5 & 0 & 14,00 & 0 & 1,50 \\
\hline 19 & -20 & 0 & 0 & 14,50 & 0 & 0,25 \\
\hline 20 & -21 & 0 & 0 & 8,00 & 0 & 0,75 \\
\hline 21 & -22 & 0 & 0 & 5,75 & 0 & 0,75 \\
\hline 22 & -23 & 0 & 0 & 3,50 & 0 & 0,50 \\
\hline 23 & -24 & 0 & 0 & $6,00 * *$ & 0 & 1,00 \\
\hline 24 & -1 & 0 & 0 & 2,75 & 0 & 0,75 \\
\hline
\end{tabular}

* início e** final do período de luz

L - luz; E - escuro 
.27.

TABEElla 13. Média do no de ovos postos por $C$. capitata, não irradiadas, nos intervalos de uma hora, em cada fotoperiodo durante a fase II (conforme Tabela 1).

\begin{tabular}{|c|c|c|c|c|c|c|}
\hline \multirow{2}{*}{\multicolumn{2}{|c|}{$\begin{array}{l}\text { Hora do } \\
\text { dia }\end{array}$}} & \multicolumn{5}{|c|}{ Fotoperiodo } \\
\hline & & $6 L-18 E$ & $18 L-6 E$ & $E-E$ & $L-L$ & $12 \mathrm{~L}-12 \mathrm{E}$ \\
\hline 1 & $-\quad: 2$ & 0 & 3,25 & 1,00 & 4,25 & 0,50 \\
\hline 2 & -3 & 0 & 0,50 & 0,75 & 3,25 & 0 \\
\hline 3 & -4 & 1,75 & 1,00 & 0 & 2,50 & 0,75 \\
\hline 4 & -5 & 0 & 0,75 & 0 & 5,00 & 0 \\
\hline 5 & -6 & 2,00 & 1,00 & 0 & 7,25 & 0,50 \\
\hline 6 & -7 & $10,00 *$ & 2,25 * & 0 & 7,50 & $0,50 *$ \\
\hline 7 & -8 & 25,00 & 11,75 & 0 & 7,50 & 1,00 \\
\hline 8 & -9 & 25,50 & $15,7.5$ & 0 & 3,00 & 2,50 \\
\hline & -10 & 33,50 & 18,75 & 0 & 1,75 & 1,00 \\
\hline 10 & -11 & 26,75 & 15,75 & 0 & 9,00 & 0,25 \\
\hline 11 & -12 & $30,60 * *$ & 16,75 & 0,50 & 5,75 & 5,00 \\
\hline 12 & -13 & 18,50 & 11,00 & 0 & 3,00 & 4,00 \\
\hline 13 & -14 & 3,75 & 17,25 & 0,25 & 4,00 & 5,25 \\
\hline 14 & -15 & 0 & 13,50 & 0 & 3,00 & 3,50 \\
\hline 15. & -16 & 0 & 23,25 & 2,25 & 3,50 & 5,00 \\
\hline 16 & -17 & 0 & 12,25 & 0,75 & 1,75 & 7,75 \\
\hline 17 & -18 & 0 & 11,75 & 0 & 5,75 & $4,25 *$ \\
\hline 18 & -19 & 0 & 19,00 & 1,50 & 7,50 & 2,25 \\
\hline 19 & -20 & 0 & 17,00 & 0 & 6,25 & 0,25 \\
\hline 20 & -21 & 0 & 23,75 & 0 & 7,25 & 0 \\
\hline 21 & -22 & 0 & 16,25 & 0,50 & 2,50 & 0 \\
\hline 22 & -23 & 0 & 7,75 & 0 & 5,25 & 0 \\
\hline 23 & -24 & 0 & $5,25 * *$ & 0,50 & 4,00 & 0 \\
\hline 24 & -1 & 0 & 6,75 & 0,75 & 6,25 & 0 \\
\hline
\end{tabular}

* início e** final do período de luz L - luz; E - escuro. 

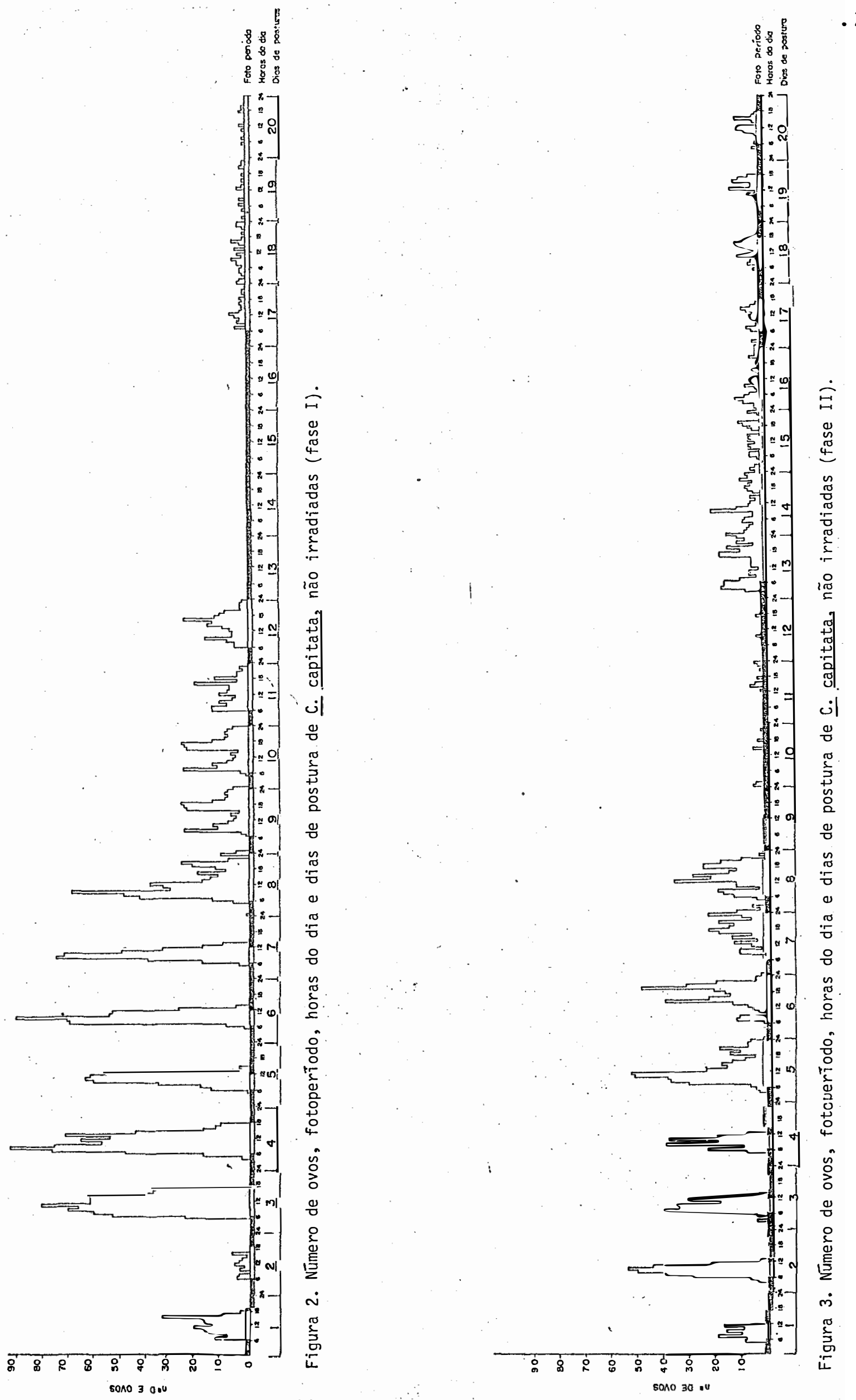
de 0:24 L:E, e que a oviposição se deu dentro das mesmas horas dos dias antecedentes e que correspondem ao fotoperiodo $18: 6 \mathrm{~L}: \mathrm{E}$.

A partir dos dados da Tabela 4, fase III, con $\underline{\text { }}$ truiu-se a Figura 4 , e a Tabela 14. Nestes, observa-se novamente a dependência da oviposição com o período de luz. Pode-se observar ainda a ocorrência de posturas em período sem luz (59 ao 89 dia). Nota-se também que estas posturas seguem o mesmo horário do fotoperíodo anterior, evidenciando o ritmo circadiano.

Com os dados obtidos na fase IV, Tabela 5, construiu-se a Figura 5 e a Tabela 15, onde são evidenciadas as observações anteriores e nota-se claramente oviposição ar ritmica, quando os insetos foram expostos em período contínuo de luz (5ㅇ ao 8 ? dia).

A partir dos dados da Tabela 6 , fase V, construiu-se a Figura 6 e Tabela 16, nos quais observa-se novamente a arritmia de oviposição da mosaa-do-Mediterrâneo,quan do expostas ao período de luz continua. 
TABELA 14. Média do no de ovos postos por $C$. capitata, não ir radiada, nos intervalos de uma hora, em cada foto periodo, durante a fase III (conforme Tabela 1).

\begin{tabular}{|c|c|c|c|c|c|c|}
\hline \multirow{2}{*}{\multicolumn{2}{|c|}{$\begin{array}{l}\text { Hora do } \\
\text { dia }\end{array}$}} & \multicolumn{4}{|c|}{ Fotoperiodo } & \multirow[b]{2}{*}{$6 L-18 E$} \\
\hline & & $18 L-6 E$ & $E-E$ & $L-L$ & $12 \mathrm{~L}-12 \mathrm{E}$ & \\
\hline 1 & -2 & 0 & 0,75 & 39,25 & 0 & 0 \\
\hline 2 & -3 & 0 & 0,5 & 40,0 & 0 & 0 \\
\hline 3 & -4 & 1,5 & 0,75 & 33,75 & 0 & 0 \\
\hline 4 & -5 & 1,0 & 2,5 & 21,25 & 0 & 0 \\
\hline 5 & -6 & 7,5 & 0 & 17,00 & 0 & 2,25 \\
\hline 6 & -7 & $31,5 *$ & 0 & 13,5 & $2,0^{*}$ & $12,25 *$ \\
\hline 7 & -8 & 32,5 & 0 & 22,25 & 7,75 & 16,0 \\
\hline 8 & -9 & 37,0 & 0 & 16,25 & 10,25 & 17,0 \\
\hline & -10 & 37,25 & 1,5 & 15,75 & 12,0 & 11,0 \\
\hline 10 & -11 & 40,5 & 2,25 & 17,75 & 18,25 & 10,2 \\
\hline 11 & -12 & 56,75 & 3,0 & 20,25 & 12,75 & $12,5 * *$ \\
\hline 12 & -13 & 49,5 & 5,25 & 19,75 & 11,5 & 6,25 \\
\hline 13 & -14 & 67,75 & $.15,25$ & 17,0 & 23,75 & 1,0 \\
\hline 14 & -15 & 61,5 & 12,75 & 14,25 & 21,75 & 0,25 \\
\hline 15 & -16 & 64,0 & 13,75 & 15,75 & 16,5 & 0 \\
\hline 16 & -17 & 42,25 & 11,45 & 11,25 & 13,0 & 0,25 \\
\hline 17 & -18 & 40,75 & 10,5 & 12,5 & $10,0 * *$ & 0 \\
\hline 18 & -19 & 46,75 & 10,5 & 7,0 & 2,25 & 0 \\
\hline 19 & -20 & 60,5 & 3,0 & 14,5 & 0,75 & 0 \\
\hline 20 & -21 & 49,5 & 15,5 & 16,25 & 0 & 0 \\
\hline 21 & -22 & 48,0 & 11,75 & 16,75 & 0 & 0 \\
\hline 22 & -23 & 37,75 & 6,25 & 17,5 & 0 & 0 \\
\hline 23 & -24 & $23,75 * *$ & 3,75 & 11,25 & 0 & 0 \\
\hline 24 & -1 & 6,25 & 5,75 & 13,0 & 0 & 0 \\
\hline
\end{tabular}

*início e** final do período de luz.

L - lUz; E - escuro 
TABELA 15. Média do no de ovos postos por $C$. capitata,não ir radiada, nos intervalos de uma hora, em cada foto periodo, durante a fase IV (conforme Tabela 1).

\begin{tabular}{|c|c|c|c|c|c|c|}
\hline \multirow{2}{*}{\multicolumn{2}{|c|}{$\begin{array}{l}\text { Hora do } \\
\text { dia }\end{array}$}} & \multicolumn{5}{|c|}{ Fotoperiodo } \\
\hline & & $E-E$ & $L-I$ & $12 \mathrm{~L}-12 \mathrm{E}$ & $6 L-18 E$ & $18 L-6 E$ \\
\hline 1 & -2 & 3,25 & 65,75 & 2,5 & 0 & 0 \\
\hline 2 & -3 & 1,0 & 67,75 & 1,5 & 0 & 0 \\
\hline 3 & -4 & 2,25 & 72,0 & 1,75 & 0 & 0 \\
\hline 4 & -5 & 1,25 & 55,25 & 2,5 & 0 & 0 \\
\hline 5 & -6 & 2,0 & 50,75 & 4,5 & 0 & 0 \\
\hline 6 & -7 & 0 & 53,25 & $5,0 *$ & $5,75 *$ & $3,0 *$ \\
\hline 7 & -8 & 0 & 47,75 & 6,5 & 12,5 & 3,5 \\
\hline 8 & -9 & 3,0 & 34,0 & 6,0 & 12,25 & 11,75 \\
\hline 9 & -10 & 6,0 & 50,25 & 10,75 & 13,0 & 11,5 \\
\hline 10 & -11 & 16,0 & 48,25 & 8,5 & 10,25 & 14,25 \\
\hline 11 & -12 & 11,0 & 35,25 & 12,0 & $12,0 * *$ & 11,75 \\
\hline 12 & -13 & 14,5 & 35,5 & 9,75 & 10,75 & 11,0 \\
\hline 13 & -14 & 19,25 & 30,25 & 19,5 & 5,5 & 7,25 \\
\hline 14 & -15 & 22,75 & 29,5 & 18,5 & 0 & 4,0 \\
\hline 15 & -16 & 28,5 & 34,5 & 14,25 & 0 & 10,5 \\
\hline 16 & -17 & 24,0 & 31,75 & 16,25 & 0 & 12,75 \\
\hline 17 & -18 & 18,75 & 31,0 & $8,25 * *$ & 0 & 9,0 \\
\hline 18 & -19 & 19,5 & 23,75 & 3,5 & 0 & 6,75 \\
\hline 19 & -20 & 13,25 & 18,75 & 0,25 & 0 & 4,0 \\
\hline 20 & -21 & 10,0 & 20,5 & 0,5 & 0 & 3,25 \\
\hline 21 & -22 & 8,25 & 36,00 & 1,0 & 0 & 2,25 \\
\hline 22 & -23 & 6,50 & 35,25 & 0,75 & 0 & 3,25 \\
\hline 23 & -24 & 6,75 & 34,75 & 0 & 0 & $2,5 * *$ \\
\hline 24 & -1 & 15,75 & 30,75 & 0 & 0 & 1,0 \\
\hline
\end{tabular}

*inicioe ** final do período de luz L - luz; E - Escuro 

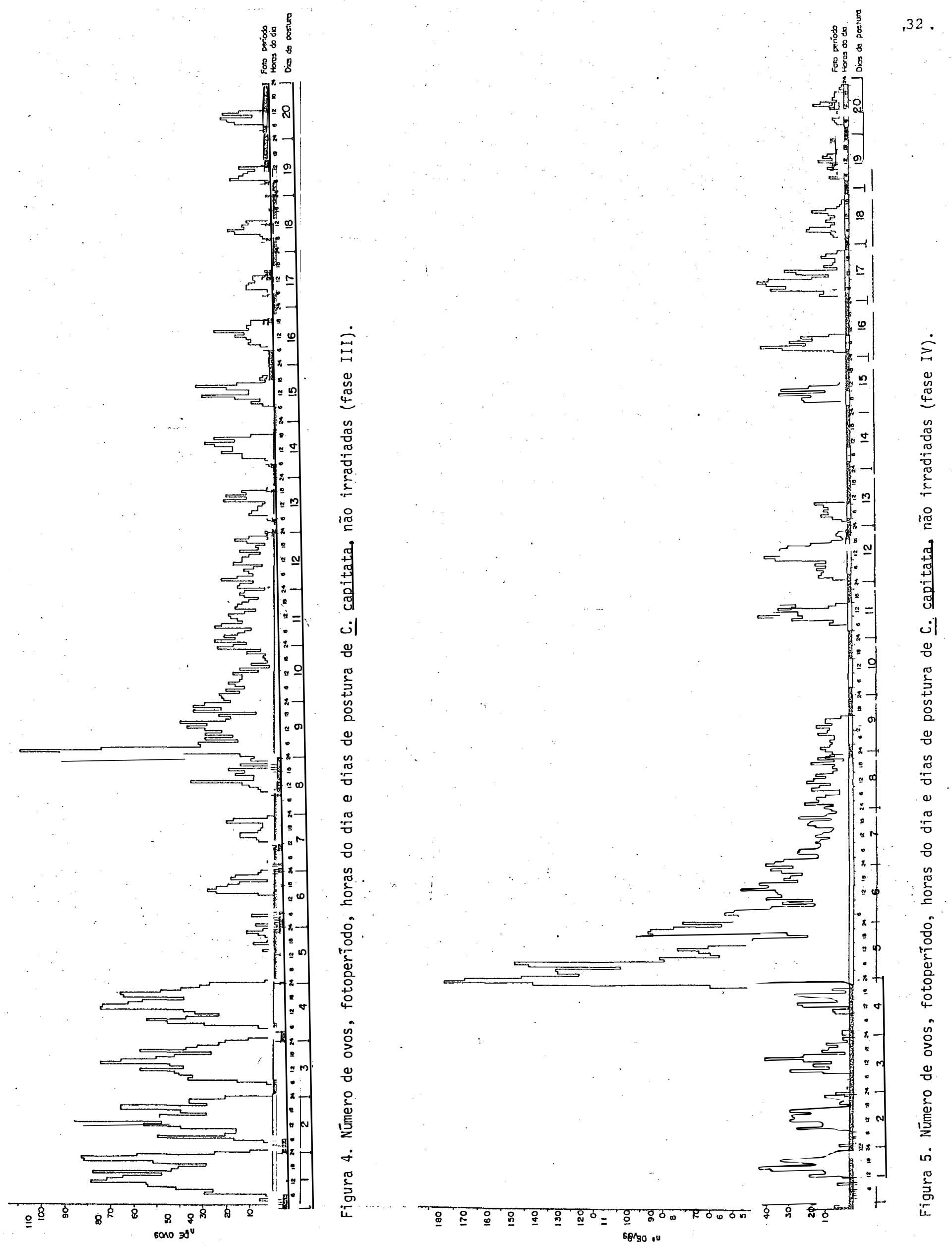
TABBELA 16. Média do no de ovos postos por C. capitata, não ir radiada, nos intervalos de uma hora, em cada foto periodo, durante a fase $\mathrm{V}$ (conforme Tabela 1).

\begin{tabular}{|c|c|c|c|c|c|c|}
\hline \multirow{2}{*}{\multicolumn{2}{|c|}{$\begin{array}{l}\text { Hora do } \\
\text { dia }\end{array}$}} & \multicolumn{4}{|c|}{ Fotoperiodo } & \multirow[b]{2}{*}{$E-E$} \\
\hline & & $L-L$ & $12 \mathrm{~L}-12 \mathrm{E}$ & $6 L-18 E$ & $18 L-6 E$ & \\
\hline $1-$ & -2 & 31,75 & 0,50 & 0 & 0 & 0 \\
\hline 2 & 3 & $47 ; 25$ & 0 & 0 & 0 & 0,5 \\
\hline 3. & -4 & 26,75 & 0,25 & 0 & 0 & 0,25 \\
\hline 4 & -5 & 24,75 & 0 & 0 & 0 & 0 \\
\hline 5. & 6 & 20,25 & 0 & 0,25 & 0,50 & 0 \\
\hline $6-$ & 7 & 18,75 & $2,25 *$ & 2,50 * & $3,0 *$ & 0 \\
\hline 7 & -8 & 24,25 & 12,25 & 19,50 & 7,50 & 0 \\
\hline 8 & -9 & 25,00 & 20,00 & 31,50 & 11,75 & 0 \\
\hline 9 . & -10 & 28,75 & 21,00 & 30,25 & 12,50 & 0 \\
\hline 10 & -11 & 28,50 & 21,25 & 39,25 & 11,25 & 0,25 \\
\hline 11 & -12 & 23,75 & 28,50 & $34,75 * *$ & 14,50 & 0,75 \\
\hline 12 & -13 & 17,50 & 39,00 & 28,50 & 12,75 & 2,0 \\
\hline 13 & -14 & 12,75 & 36,75 & 7,00 & 9,25 & 1,25 \\
\hline 14 & -15 & 24,50 & 38,25 & 1,25 & 9,75 & 0 \\
\hline 15 & -16 & 19,00 & 45,25 & 0 & 13,00 & 2,0 \\
\hline 16 & -17 & 10,25 & 25,75 & 1,25 & 13,25 & 0,50 \\
\hline 17 & -18 & 18,00 & $24,75 * \star$ & 0 & 5,75 & 0,75 \\
\hline 18 & -19 & 14,25 & 9,25 & 0 & 9,50 & 0 \\
\hline 19 & -20 & 24,75 & 3,00 & 1,25 & 6,25 & 0 \\
\hline 20 & -21 & 27,25 & 0,75 & 0,50 & 8,00 & 0 \\
\hline 21 & -22 & 32,25 & 0 & 0 & 5,00 & 0 \\
\hline 22 & -23 & 27,50 & 1,25 & 0 & 3,25 & 0 \\
\hline 23 & -24 & 20,25 & 0,75 & 0 & $5,50 * *$ & 0 \\
\hline 24 & -1 & 18,50 & 0 & 0 & 1,00 & 0 \\
\hline
\end{tabular}

*inicio e** final do periodo de luz

L - luz; E - escuro 
5.2. Etapa 2 - Insetos irradiados com 10 Gy de raios gama, no 6 ? dia do perỉodo pupal

A partir dos dados das Tabelas 7, 8, 9, 10 e 11, fases VI, VII, VIII, IX e X, construiram-se as Figuras $7,8,9,10$ e 11 e as Tabelas 17, 18, 19, 20 e 21 , respectivamente. Através destas Figuras e Tabelas, pode-se verificar as mesmas observações feitas às Figuras e Tabelas anteriores, com excesção da fecundidade, que foi menor devido a irradiação dos insetos. Esta redução do nủmero de ovos em fêmeas irradiadas é normal devido às alterações fisiológicas causadas pelas radiações no aparelho reprodutor das fêmeas (CAVALLORO e DELRIO, 1970). 


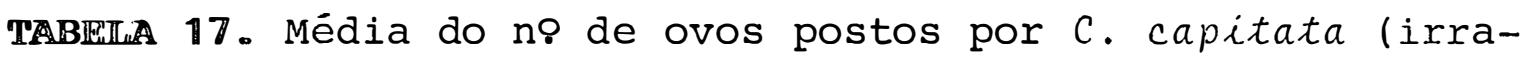
diadas), nos intervalos de uma hora, em cada fotoperiodo, durante a fase VI (conforme Tabela 1).

\begin{tabular}{|c|c|c|c|c|c|c|}
\hline \multirow{2}{*}{\multicolumn{2}{|c|}{$\begin{array}{l}\text { Hora do } \\
\text { dia }\end{array}$}} & \multicolumn{4}{|c|}{ Fotoperíodo } & \multirow[b]{2}{*}{$E-E$} \\
\hline & & $L-L$ & $18 L-6 E$ & $12 L-12 E$ & $6 L-18 E$ & \\
\hline 1 & -2 & 8,25 & 2,25 & 1,0 & 0 & 0 \\
\hline 2 & -3 & 10,50 & 1,25 & 0 & 0 & 0 \\
\hline 3 & -4 & 6,25 & 0 & 0 & 0 & 0 \\
\hline 4 & -5 & 9,25 & .0 & 0 & 0 & 0 \\
\hline 5 & -6 & 10,75 & 0 & 0 & 0 & 0 \\
\hline 6 & -7 & 4,25 & $3,75 *$ & $1,0 *$ & $2,5 *$ & 0 \\
\hline 7 & -8 & 3,0 & 4,0 & 3,75 & 2,0 & 0,5 \\
\hline 8 & -9 & 3,25 & 4,75 & 2,5 & 2,0 & 0,25 \\
\hline 9 & -10 & 6,25 & 2,0 & 4,0 & 4,0 & 0 \\
\hline 10 & -11 & 3,5 & 1,25 & 1,75 & 4,0 & 0,75 \\
\hline 11 & -12 & 5,5 & 2,25 & 3,25 & $6,75 * *$ & 0 \\
\hline 12 & -13 & 4,0 & 2,0 & 4,75 & 4,25 & 0 \\
\hline 13 & -14 & 6,5 & 3,75 & 11,25 & 2,25 & 0 \\
\hline 14 & -15 & 4,5 & 6,5 & 6,0 & 1,5 & 0 \\
\hline 15 & -16 & 1,75 & 5,25 & 10,75 & 1,5 & 0 \\
\hline 16 & -17 & 3,75 & 6,25 & 4,75 & 2,0 & 0 \\
\hline 17 & -18 & 4,5 & 8,0 & $8,0 * *$ & 0,25 & 0 \\
\hline 18 & -19 & 0,75 & 8,5 & 7,75 & 0,50 & 0,50 \\
\hline 19 & -20 & 3,75 & 10,0 & 4,75 & 0 & 0 \\
\hline 20 & -21 & 2,75 & 12,25 & 0,75 & 0 & 0 \\
\hline 21 & -22 & 6,75 & 9,75 & 1,25 & 0 & 0 \\
\hline 22 & -23 & 12,0 & 6,50 & 0 & 0 & 0 \\
\hline 23 & -24 & 9,0 & $2,50 * \star$ & 0 & 0 & 0,25 \\
\hline 24 & -1 & 4,25 & 3,5 & 0 & 0 & 0 \\
\hline
\end{tabular}

*início e**inal do período de luz

L - luz; E - escuro 

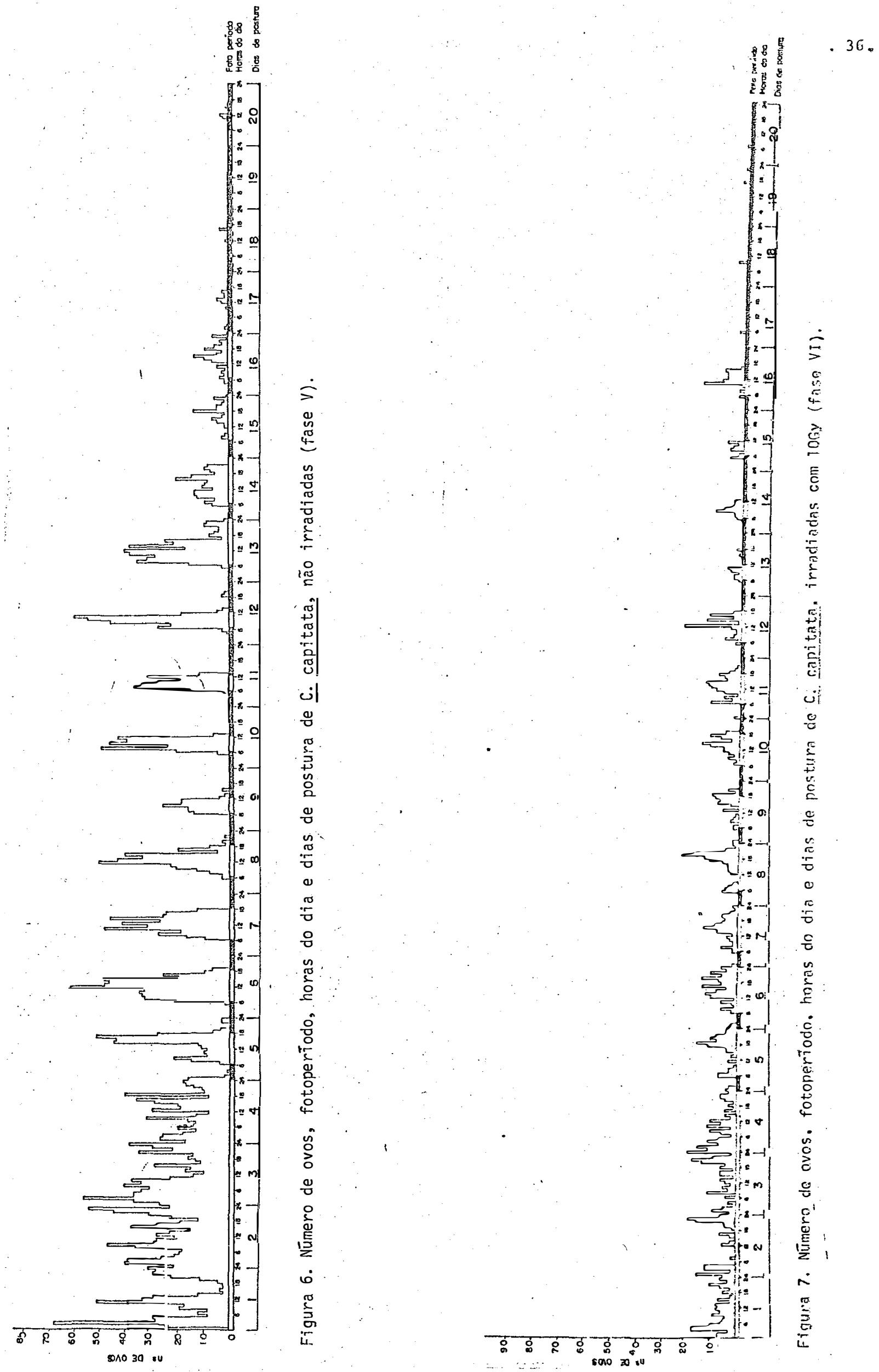
TABEILA 18. Médias do no de ovos postos por C. capitata (irra diadas), nos intervalos de uma hora, em cada foto periodo, durante a fase VII (conforme Tabela 1).

\begin{tabular}{|c|c|c|c|c|c|c|}
\hline \multirow{2}{*}{\multicolumn{2}{|c|}{$\begin{array}{l}\text { Hora do } \\
\text { dia }\end{array}$}} & \multicolumn{5}{|c|}{. $\quad$ Fotoperíodo } \\
\hline & & $18 L-6 E$ & $12 L-12 E$ & $6 L-18 E$ & $E-E$ & $L-L$ \\
\hline 1 & -2 & 3 & 0 & 0 & 0 & 4,75 \\
\hline 2 & -3 & 1,5 & 0 & 0 & 0 & 7,5 \\
\hline 3 & -4 & 3,5 & 0 & 0 & 0,25 & 13,5 \\
\hline 4 & -5 & 0 & 3,25 & 9,0 & 1,5 & 15,25 \\
\hline 5 & -6 & 1,25 & 13,5 & 37,75 & 1,25 & 16,75 \\
\hline 6 & -7 & $5,75 *$ & $29,0 *$ & $45,75 *$ & 2,0 & 14,25 \\
\hline 7 & -8 & 19,0 & 33,5 & 39,5 & 2,75 & 13,75 \\
\hline 8 & -9 & 25,5 & 45,0 & 64,0 & 4,0 & 15,0 \\
\hline 9 & -10 & 20,5 & 48,0 & 55,5 & 5,0 & 15,0 \\
\hline 10 & -11 & 27,5 & 48,75 & 51,75 & 4,75 & 14,75 \\
\hline 11 & -12 & 24,0 & 55,25 & $34,25 * *$ & 8,25 & 9,5 \\
\hline 12 & -13 & 13,75 & 43,75 & 13,25 & 4,25 & 4,5 \\
\hline 13 & -14 & 22,0 & 55,75 & 0,25 & 7,75 & 7,25 \\
\hline 14 & -15 & 19,25 & 45,25 & 1,25 & 4,5 & 5,5 \\
\hline 15 & -16 & 24,75 & 42,25 & 0,25 & 1,0 & 8,5 \\
\hline 16 & -17 & 28,0 & 27,5 & 0,5 & 1,5 & 6,5 \\
\hline 17 & $=18$ & 27,0 & $8,25 * *$ & 0 & 0,25 & 5,0 \\
\hline 18 & -19 & 18,75 & 2,5 & 0 & 0,25 & 5,25 \\
\hline 19 & -20 & 26,75 & 2,0 & 0 & 0,5 & 3,75 \\
\hline 20 & -21 & 17,75 & 3,5 & 0 & 0 & 4,0 \\
\hline 21 & -22 & 24,25 & 1,5 & 0 & 0 & 5,0 \\
\hline 22 & -23 & 13,75 & 0 & 0 & 0 & 3,5 \\
\hline 23 & -24 & $14,75 * *$ & 0 & 0 & 0 & 4,75 \\
\hline 24 & -1 & 10,25 & 0 & 0 & 0 & 4,25 \\
\hline
\end{tabular}

* início e* final do período de luz

L - Iuz; E - escuro 
.38 .

TPABEPIIA 19. Média do no de ovos postos por C. capitata (irradiadas), nos intervalos de uma hora, em cada foto período, durante a fase VIII (conforme Tabela 1).

\begin{tabular}{|c|c|c|c|c|c|c|c|}
\hline \multirow{2}{*}{\multicolumn{3}{|c|}{$\begin{array}{l}\text { Hora do } \\
\text { dia }\end{array}$}} & \multicolumn{5}{|c|}{ Fotoperíodo } \\
\hline & & & $12 \mathrm{~L}-12 \mathrm{E}$ & $6 L-18 E$ & $E-E$ & $L-L$ & $18 L-6 E$ \\
\hline 1 & - & 2 & 0 & 0 & 0 & 12,25 & 0 \\
\hline 2 & - & 3 & 0 & 0 & $0,7.5$ & 13,0 & 0 \\
\hline 3 & - & 4 & 0 & 0 & 0 & 11,75 & 0 \\
\hline 4 & - & 5 & 0 & 0 & 0,5 & 14,75 & 0 \\
\hline 5 & - & 6 & 1,0 & 0,75 & 1,25 & 8,75 & 0 \\
\hline 6 & - & 7 & $1,25 *$ & $4,75 *$ & 2,5 & 5,5 & 0 * \\
\hline 7 & - & 8 & 8,25 & 21,75 & 0,5 & 11,75 & 0 \\
\hline 8 & - & 9 & 14,5 & 31,25 & 0 & 4,75 & 1,25 \\
\hline 9 & - & 10 & 31,25 & 42,0 & 0,75 & 2,0 & 0 \\
\hline 10 & - & 11 & 30,0 & 48,0 & 1,0 & 3,0 & 0,25 \\
\hline 11 & - & 12 & 46,75 & $52,75 * *$ & 0,75 & 2,75 & 0 \\
\hline 12 & - & 13 & 46,25 & 42,5 & 0,5 & 2,5 & 0,75 \\
\hline 13 & - & 14 & 47,25 & 7,75 & 0,25 & 1,75 & 0 \\
\hline 14 & - & 15 & 44,0 & 2,75 & 0,25 & 3,0 & 1,0 \\
\hline 15 & - & 16 & 32,25 & 0,5 & 0,5 & 2,75 & 1,0 \\
\hline 16 & - & 17 & 26,25 & 0,25 & 0,5 & 1,75 & 2,25 \\
\hline 17 & & 18 & $23,5 * \star$ & 1,0 & 0,5 & 1,75 & 2,25 \\
\hline 18 & & 19 & 16,5 & 0,75 & 0,25 & 1,50 & 0,75 \\
\hline 19 & & 20 & 2,5 & 0 & 0 & 2,75 & 0,75 \\
\hline 20 & & 21 & 1,25 & 0,5 & 0 & 0,75 & 0 \\
\hline 21 & & 22 & 1,25 & 0 & 0 & 2,0 & 0 \\
\hline 22 & & 23 & 0,5 & 0,5 & 0 & 1,75 & 0,5 \\
\hline 23 & & 24 & 0 & 0,25 & 0 & 0,5 & $0 * \star$ \\
\hline 24 & - & 1 & 0 & 0,75 & 0,75 & 1,0 & 0 \\
\hline
\end{tabular}

*início e** final do período de luz

L - luz; E - escuro 

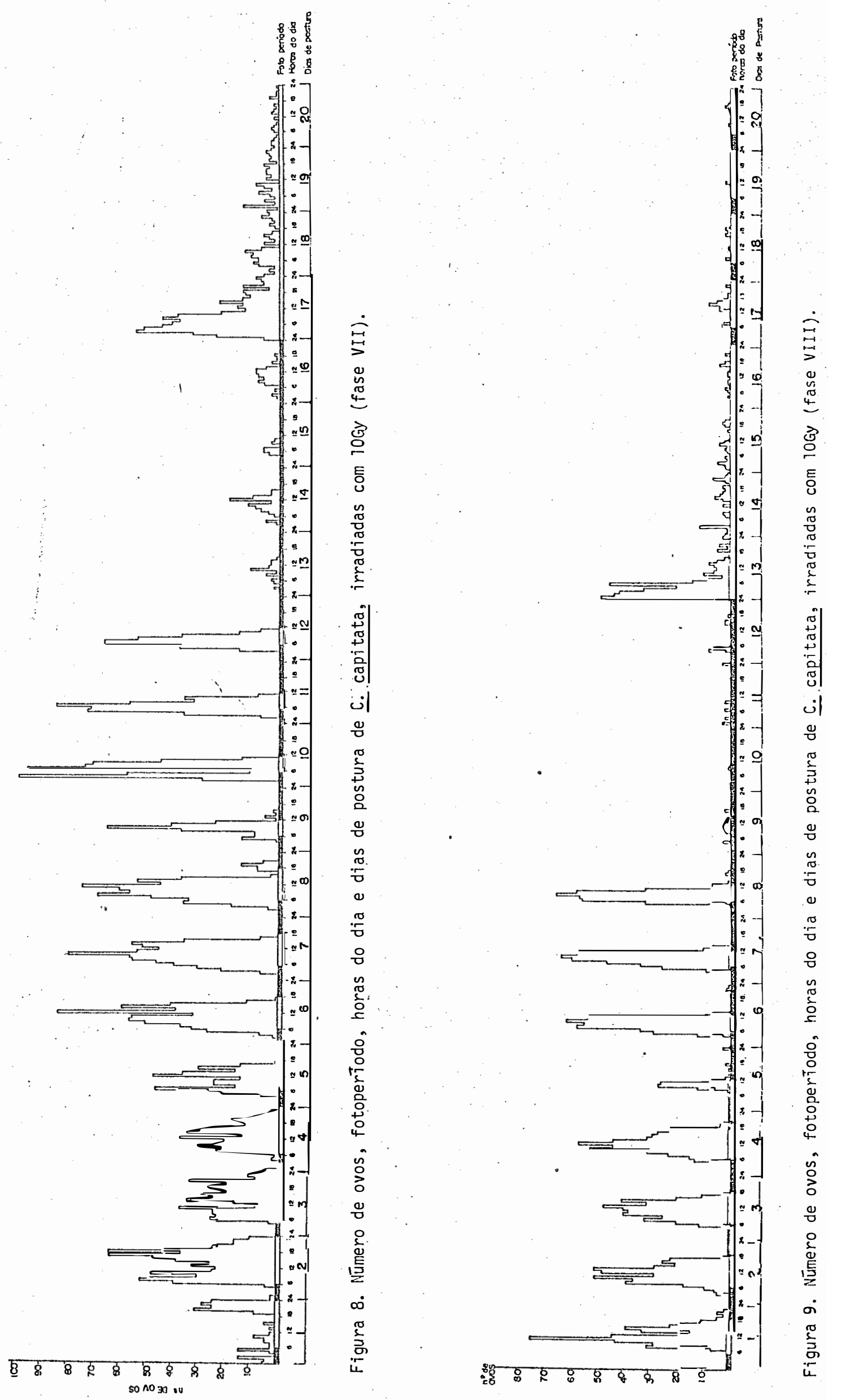
.40 .

TABELLA 20. Média do no de ovos postos por $C$. capitata (irradiadas), nos intervalos de uma hora, em cada foto periodo, durante a fase IX (conforme Tabela 1).

\begin{tabular}{|c|c|c|c|c|c|c|c|}
\hline \multirow{2}{*}{\multicolumn{3}{|c|}{$\begin{array}{l}\text { Hora do } \\
\text { dia }\end{array}$}} & \multicolumn{5}{|c|}{ Fotoperiodo } \\
\hline & & & $6 L-18 E$ & $E-E$ & $L-L$ & $18 I-6 E$ & $12 \mathrm{~L}-12 \mathrm{E}$ \\
\hline 1 & - & 2 & 0 & 0,25 & 8,75 & 0 & 0 \\
\hline 2 & - & 3 & 0 & 0 & 16,25 & 0,25 & 0 \\
\hline 3 & - & 4 & 0 & 0 & 16,75 & 2,25 & 0 \\
\hline 4 & - & 5 & 1,75 & 1,25 & 14,00 & 0,50 & 0 \\
\hline 5 & - & 6 & 11,25 & 2,00 & 9,25 & 0,25 & 0 \\
\hline 6 & - & 7 & $20,25 *$ & 1,50 & 15,25 & $1,25 *$ & $0 *$ \\
\hline 7 & - & 8 & 27,75 & 1,00 & 8,50 & 1,75 & 0 \\
\hline 8 & - & 9 & 29,50 & 4,00 & 11,75 & 2,50 & 1,25 \\
\hline 9 & & 10 & 44,50 & 5,75 & 13,50 & 0,25 & 0,50 \\
\hline 10 & - & 11 & 36,00 & 6,25 & 10,75 & 0,75 & 2,25 \\
\hline 11 & - & 12 & $29,00 * *$ & 3,25 & 6,00 & 0,50 & 1,0 \\
\hline 12 & - & 13 & 21,50 & 6,25 & 2,50 & 0,50 & 0 \\
\hline 13 & - & 14 & 1,75 & 4,00 & 2,50 & 1,50 & 0,75 \\
\hline 14 & - & 15 & 2,00 & 4,00 & 2,50 & 1,00 & 1,25 \\
\hline 15 & - & 16 & 1,50 & 1,00 & 4,75 & 1,00 & 1,25 \\
\hline 16 & - & 17 & 0,50 & 2,00 & 3,50 & 3,50 & 1,25 \\
\hline 17 & - & 18 & 0 & 0 & 1,50 & 3,00 & $0,25 * *$ \\
\hline 18 & - & 19 & 1,75 & 0,50 & 4,00 & 0,50 & 0,50 \\
\hline 19 & - & 20 & 0 & 0 & 1,25 & 1,00 & 0 \\
\hline 20 & - & 21 & 0 & 1,75 & 2,00 & 1,50 & 0 \\
\hline 21 & - & 22 & 0 & 0 & 2,50 & 0,25 & 0 \\
\hline 22 & - & 23 & 0,75 & 0,25 & 5,00 & 1,75 & 0 \\
\hline 23 & - & 24 & 0 & 1,50 & 2,50 & $1,50 * *$ & 0 \\
\hline 24 & - & 1 & 0,5 & 3,50 & 5,25 & 0 & 0 \\
\hline
\end{tabular}

* início e** final do período de luz

L - luz; E - escuro 
TABELA 21. Média do no de ovos postos por $C$. capitata (irradiadas), nos intervalos de uma hora, em cada foto período, durante a fase X (conforme Tabela 1).

\begin{tabular}{|c|c|c|c|c|c|c|}
\hline \multirow{2}{*}{\multicolumn{2}{|c|}{$\begin{array}{l}\text { Hora do } \\
\text { dia }\end{array}$}} & \multicolumn{5}{|c|}{ Fotoperiodo } \\
\hline & & $E-E$ & $\mathrm{~L}-\mathrm{L}$ & $18 \mathrm{~L}-6 \mathrm{E}$ & $12 L-12 E$ & $6 L-18 E$ \\
\hline 1 & -2 & 5,25 & 47,75 & 1,00 & 0 & 0 \\
\hline 2 & -3 & 8,00 & 65,00 & 0,25 & 0 & 0 \\
\hline 3 & -4 & 2,75 & 53,25 & 0 & 0 & 0 \\
\hline 4 & -5 & 1,00 & 38,00 & 0 & 0 & 0 \\
\hline 5 & -6 & 3,00 & 37,00 & 0,25 & 0 & 0 \\
\hline 6 & -7 & 2,75 & 40,50 & $7,50 *$ & 0 * & $3,75 *$ \\
\hline 7 & -8 & 3,25 & 39,00 & 16,00 & 1,25 & 7,75 \\
\hline 8 & -9 & 3,25 & 56,00 & 13,25 & 2,00 & 10,00 \\
\hline 9 & -10 & 2,50 & 53,75 & 10,50 & 6,50 & 10,00 \\
\hline 10 & -11 & 4,00 & 50,25 & 7,00 & 9,00 & 12,00 \\
\hline 11 & -12 & 7,25 & 52,75 & 15,50 & 6,25 & $10,75 * *$ \\
\hline 12 & -13 & 13,00 & 35,50 & 16,50 & 7,25 & 4,75 \\
\hline 13 & -14 & 15,50 & 36,00 & 17,25 & 12,25 & 2,00 \\
\hline 14 & -15 & 25,75 & 29,25 & 23,75 & 11,50 & 0,50 \\
\hline 15 & -16 & 29,00 & 23,25 & 29,00 & 13,00 & 0,50 \\
\hline 16 & -17 & 22,00 & 22,75 & 37,00 & 18,75 & 0,50 \\
\hline 17 & -18 & 27,50 & 25,00 & 18,75 & $17,75 * *$ & 0 \\
\hline 18 & -19 & 22,75 & 20,00 & 21,25 & 10,25 & 0 \\
\hline 19 & -20 & 21,25 & 12,75 & 13,50 & 4,50 & 0 \\
\hline 20 & -21 & 19,75 & 11,25 & 12,00 & 2,25 & 0 \\
\hline 21 & -22 & 14,25 & 20,75 & 11,00 & 0,50 & 0 \\
\hline 22 & -23 & 19,25 & 17,25 & 3,50 & 0,75 & 0 \\
\hline 23 & -24 & 13,75 & 22,75 & 5,75 & 1,00 & 0 \\
\hline 24 & -1 & 19,00 & 20,50 & 2,75 & 0 & 0 \\
\hline
\end{tabular}

* início e** final do período de luz

L - luz; E - escuro 

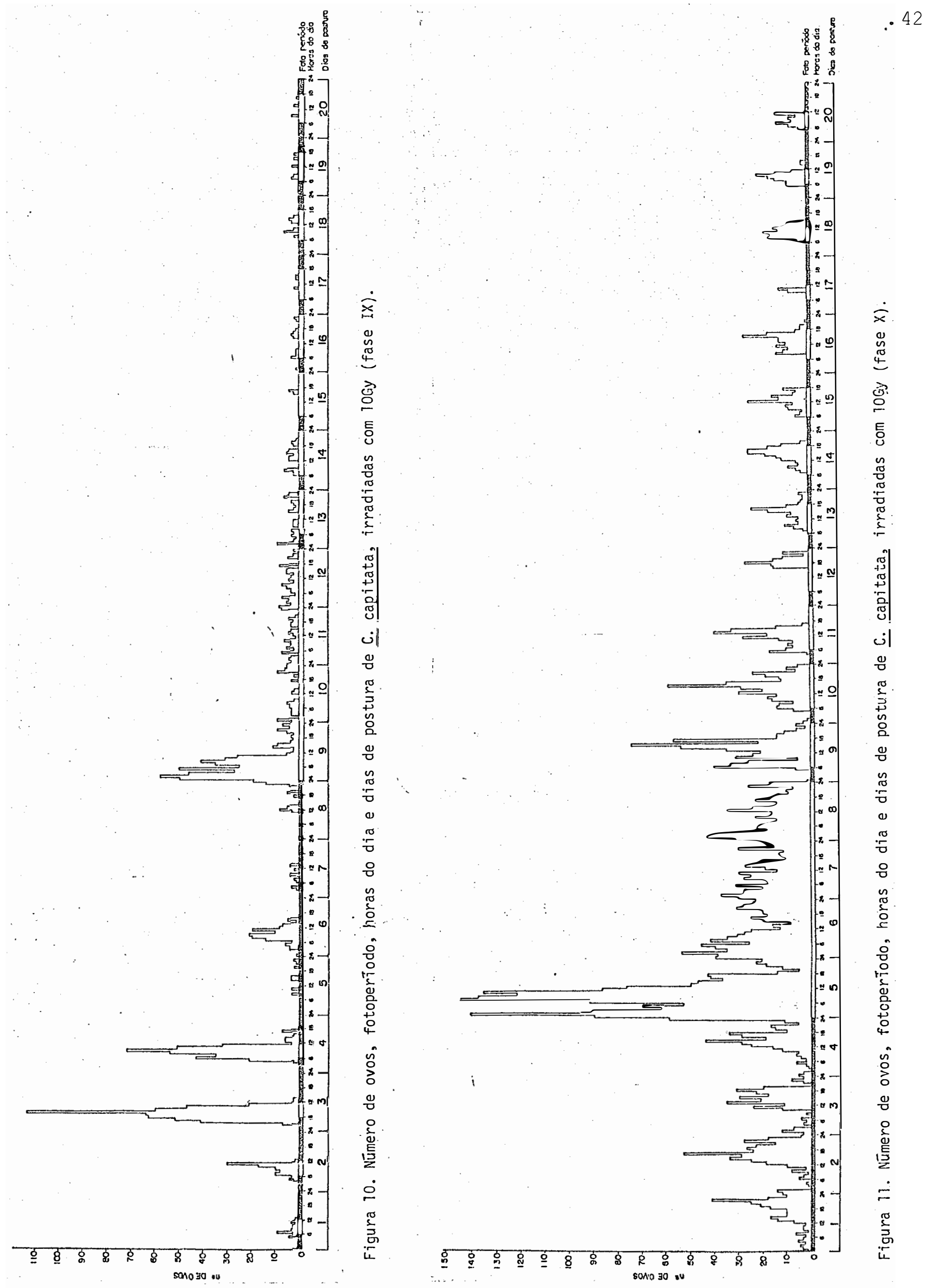


\section{CONCLUSŌES}

Nas condições em que foi realizado este traba lho e conforme os resultados obtidos, pode-se concluir que:

Existe uma estreita dependência da luz para a oviposição desse inseto, embora tenha ocorrido postura nos períodos sem luz.

O início do período de luz estimula a oviposi ção e a sua repetição no mesmo horário em dias subsequentes, provoca a manifestação de um ritmo circadiano de oviposição.

Os insetos quando submetidos ao período sem luz, por vários dias consecutivos, ovipositam no mesmo ritmo circadiano do fotoperíodo anterior, com redução do número de ovos.

A manifestação do rítmo circadiano não e evi- 
.44 .

dente, quando se expõe os insetos à 24 horas de luz diária.

A radiação gama de 10 Gy influi negativamente sobre a oviposição; diminuindo o número de ovos postos, entretanto, não afetou o rítmo circadiano. 


\section{Literatura CitADA}

ALLEMAND, R., P. FOUILLET, J.R. DAVID, 1984。 Genetic variability of circadian rhythm of oviposition in natural populations of Drosophila melanogaster. Genet. Sel.Evol., $\underline{16}(1): 27-44$.

ALLEMAND, R., J.R. DAVID, 1984. Genetic analysis of the circadian oviposition rhythm in Drosophila melanogaster: Effects of driff in laboratory strains. Behav. Genet. $14(1): 31-44$.

BENSCHOTER, C.A., 1970. Influence of light manipulation on diapause of Heliothis zea and H. virescens. Ann. Entomol. Soc. Am., 61(5): 1272-1274。 
CAVALLORO, R. e G. DELRIO, 1970. Stude sulla radiosterilizzazione di Ceratitis capitata, Wiedemanne sul comportamento dell'insetto normale e sterile. Redia, 52: 511-547.

CAUSSE, R., 1974. Etude d'um rythme circadien du comportement de prénymfose chez Ceratitis capitata Wiedemann (Diptère Trypetidae). Ann. Zool. Ecol. Anim. ㅁ⑷: 475-498 .

CONSTANTINOU, C., 1984. Circadian rhythm of oviposition in the blood sucking bugs, Triatoma phyllosoma, T. infestans and Paustrongylus megistus (Hemiptera: Reduviidae). J. Intérdisciplinary Cycle Res., 15(3): 203-212.

ENGLERT, S.L., 1974. Avicultura. Ed. Centaurus Ltda.

FERREIRA, M.J.M. e J.R.P. PARRA, 1985. Efeito do fotoperíodo no ciclo biológico de Mocis latipes (Guenèe, 1852) (Le pidoptera: Noctuidae) em condições de laboratório. An. Soc. Entomol. Brasil., 14 (1): 89-95.

GREENFIELD, M.D. e M.G. KARANDINOS, 1976. Oviposition rhythm of Synanthedon pictipes under a 16:8 L.D photoperiod and various thermoperiods. Environ. Entomol. Soc. Am. 5: 712-713.

HAVERTY, M.I. e G.W. WARE, 1970. Circadian sensitivity and dosage-rate response to $\mathrm{x}$-irradiation in the pink bollworm. J.Econ. Entomol., 63 (4): 1296-1300. 
HSIAO, H.S., 1978. Circadian activity of Heliothis zea at different temperatures studied with and acoustic actograph. Ann. Entomol. Soc. Am. 71: 115-120.

LAUDEHO, Y., C. IIIAROPOUIJOS E M. CANARD, 1978. Etude, pendant la période automnale, du rythme de sortie hors des fruits des larves du dernier áge de la Mouche de l'Olive Dacus oleae (Gmel.) (Diptera, Trypetidae). Ann. Zool. Ecol. anim., 10(1): 37-50.

MARCOVITCH, S., 1924. The migration of the Aphididae and the appearance of the sexual forms as affected by the relative length of daily exposure. J. Agr. Res. 27: 513-522 .

MARICONI, F.A.M。e S. IBA, 1955. A môsca do Mediterrâneo. o Biológico 21(2): 17-23.

PARRA, J.R.P., A.B.P. MELO, B.P. MAGALHÃES, S. SILVEIRA NETO e P.S.M. BOTELHO, 1983. Efeito do fotoperíodo no ciclo biológico de Diatraea saccharalis. Pesquisa Agropecuária Brasizeira. 18(5): 462-472.

PITTENDRIGH, C.S. e D.H. MINIS, 1972. Circadian systems: longevity as a function of circadian resonance in Drosophilc melanogaster. Proc. Nat. Acad. Sci., USA, 69(6): 1537-1539. 
.48 .

PROGNÓSTICO, IEA, 1984。São Paulo, 13. 229 p.

ZOTOV, V.A., 1983. Exogenous and endogenous components of the diel rhythm of activity in coccinella septempunctata (Coleoptera, Coccinellidae). 20ol. 2h.. 62 (11): 1654-1662 . 